DISCUSSIO

\title{
RADIUS ODER COLUS? \\ TEXTILHANDWERK UND UMWELTVERÄNDERUNG IM SPÄTKAISERZEITLICHEN PANNONIEN
}

\author{
RÓBERT MÜLLER
}

mullerrobi@gmail.com

\begin{abstract}
In this paper I prove that the $20-30 \mathrm{~cm}$ long, tapered iron sticks frequently occurring in Pannonia in the $4^{\text {th }}$ century were not pin-beaters but manual distaffs used in spinning. Due to climate change the water level of Lake Balaton increased in the late imperial period. For the protection of lakeside settlements and plough-lands Emperor Galerius opened the Sió Canal, by which, however, he could only prevent the further rise of the water level. The monumental theory assuming a significant expansion of agricultural lands and a continuous exportation of grain surpluses does not stand up.
\end{abstract}

Keywords: spinning, pin-beater, climate change, Emperor Galerius, draining of Lake Balaton, grain exports

Im Jahrgang 62 der Zeitschrift Acta Archaeologica erschien meine Studie über die spätkaiserzeitlichen Spinngeräte. ${ }^{1}$ Judit Pásztókai-Szeőke beschäftigte sich mehrmals mit den eisernen Webgeräten, mit dem Webkamm (englisch: toothed werft beater) zur Verdickung des Schussfadens und mit dem Fadenordner (englisch: pin-beater) zum Ordnen der Kettenfäden. ${ }^{2}$ Der Erstere wird lateinisch pecten genannt. Sie zählte 35 Exemplare von 17 Fundorten auf. ${ }^{3}$ Ich hielt diese früher für Striegel, ${ }^{4}$ aber die mittelalterlichen Darstellungen und die rezenten Beispiele aus der Türkei beweisen eindeutig, dass ihre Bestimmung richtig ist. Ich habe dies auch anerkannt. ${ }^{5}$ Der Zweite ist ein 20-30 cm langer, in einer Richtung zugespitzter Stab mit rundem oder abgerundetem viereckigem Querschnitt. Es wurde früher für Spieß oder ,,spießartiges Haushaltsgerät“ gehalten. ${ }^{6}$ Schon János Dombay war der Meinung, dass es sich vielleicht um einen „Handrocken“ handeln könnte, ${ }^{7}$ aber Károly Sági war der Erste, der es einen Handspinnrocken nannte. ${ }^{8}$ Seine Beweisführung ist nicht eindeutig, da aus dem Grab von Balatonberény ein Eisenstab zum Vorschein kam, der in beiden Richtungen zugespitzt war. Er hat ihn als Spindel ohne Spinnwirtel bestimmt. ${ }^{9}$ Seine Illustration für „Spinnen mit einer Spindel ohne Spinnwirtel“ ist eine Darstellung aus 1490, an der das Spinnen mit einem Handspinnrocken abgebildet wurde. ${ }^{10}$ Aufgrund der antiken Darstellungen war ich davon überzeugt, dass diese zugespitzten Eisenstäbe tatsächlich Handspinnrocken waren, die im Alltag hauptsächlich aus Holz hergestellt wurden, aber im 4. Jahrhundert auch aus Eisen erzeugt werden konnten. Ich habe sie aus 31 Fundorten

MÜLLER 2011a.

${ }^{2}$ PÁszTóKai-SZEŐKe 2007; PÁsZtóKaI-SZEŐKe 2010 PÁszTóKAI-SZEŐKe 2011; PÁsZTóKAI-SzEŐKE 2012a; PÁsZTóKAISZEŐKE 2013a; PÁSZTÓKAI-SZEŐKE 2013b.

${ }^{3}$ PÁSZTÓKAI-SZEŐKe 2012a, 15-16.

${ }^{4}$ MÜLler 1982, 532; MÜLler 1994, 183.

${ }^{5}$ MÜller 2014a, 1, Fußnote 4.

${ }^{6}$ Z. B. Dombay 1957, 289; SÁGI 1960, 232; Sz. Burger 1968, 94; Sz. Burger 1972, 75; Sz. Burger 1977, 202; Sz. Burger 1979; B. VÁGÓ-BÓNA 1976, 182.

${ }^{7}$ Dombay 1957, 289.

${ }^{8}$ SÁGI 1973, 293; SÁGI 1981, 103.

${ }^{9}$ SÁGI 1973, 293.

${ }^{10}$ SÁGi 1973, Abb. 65. Die Arbeit mit dem Handspinnrocken beschrieb L. Szolnoky: Der Handspinnrocken ist ein $25-35 \mathrm{~cm}$ langer Stab, ,der untere Teil wird mit den zwei unteren Fingern erfasst, an die Spitze des Stabes wird das Werg gesteckt und mit den drei freien Fingern wird die Faser gezogen und bekommt die Grunddrehung" (SZOLNOKY 1951, 5; SZOLNOKY 1991, 57). 
gekannt. ${ }^{11}$ Wir kennen Handspinnrocken nicht nur aus Holz und Eisen, sondern auch aus Bernstein, Gagat, Glas, Knochen, Elfenbein bzw. aus dünnem Bronzeblech.

Mit ihrer Funktion und ihren Fragen, wieso sie als Beigabe in die Gräber gelegt wurden, beschäftigte sich J. Pásztókai-Szeőke. ${ }^{12}$ Sie stellte mit Recht fest, dass das Spinnen in der Antike durch die Parzen (Parcae) ein Symbol der Macht über das Schicksal des Menschen war. Außerdem wurde es als Metapher der idealen Gattin, der Fruchtbarkeit und der Gebärfähigkeit, der Tugend, der Treue und des Fleißes gedeutet. ${ }^{13}$ Diese prachtvollen Spinnrocken kommen im Allgemeinen aus reich ausgestatteten Frauengräbern zum Vorschein. Da das Spinnen eine anstrengende und schwere Arbeit ist, waren diese vornehmen Frauen wahrscheinlich nicht auf das Spinnen angewiesen. So stellt sich die Frage, ob diese Spinnrocken tatsächlich Arbeitsgeräte oder nur das Spinnen versinnbildlichende Gegenstände waren. Aufgrund ihrer Form waren sie natürlich zum Spinnen geeignet, aber meiner Meinung nach waren sie keine im Alltag benutzten Geräte. ${ }^{14}$ Dass es sich um richtige Spinnrocken handelt, wird laut J. Pásztókai-Szeőke dadurch bestätigt, dass die Römer bemerkten, die Bernstein-, Gagat- und Glasgegenstände werden durch Reiben elektrostatisch. So konnte man vor dem Spinnen die Beschmutzung aus dem Wollenwerg entfernen. ${ }^{15}$ Auch A. Facsády war der Meinung, dass die zerbrechlichen Stücke aus Glas wirkliche Spinnrocken waren. ${ }^{16}$ Die Elektrostatik hatte nicht nur einen praktischen Nutzen. In der Antike wurde diesen Materialien magische Kraft zugeschrieben, ${ }^{17}$ deshalb konnte man aus ihnen die als symbolische Gegenstände in das Grab gelegten Spinnrocken herstellen, die keine richtigen Arbeitsgeräte waren. ${ }^{18}$ Unlängst vertrat auch Kordula Gostenčnik diese Ansicht. ${ }^{19}$ Die hervorgehobene und symbolische Funktion der Spinnrocken wird auch dadurch betont, dass wir aus Pannonien 15 frühkaiserzeitliche Grabsteine kennen, an denen befreite Ehefrauen oder frei geborene Frauen mit Spindel und Spinnrocken in der Hand dargestellt sind. ${ }^{20}$ Es kann nicht ausgeschlossen werden, dass mit den aus edlem Material hergestellten, symbolischen Spinnrocken gleichzeitig auch aus organischem Material, vor allem aus Holz, erzeugte Spinnrocken als Arbeitsgeräte in Frauengräber gelangten, von diesen blieb aber keine Spur erhalten.

Die genauso langen Eisenstäbe bestimmte also J. Pásztókai-Szeőke nicht als Spinnrocken, sondern als ein anderes Webgerät, das lateinisch radius, englisch pin-beater genannt wird. Damit wurden an dem senkrechten Webstuhl mit zwei Walzen die Kettenfäden ausgehoben oder geordnet, bevor der Schussfaden mit dem Webkamm verdickt wurde. Auf Deutsch wird dieses Gerät Webstäbchen oder Fadenordner genannt. ${ }^{21}$ Worauf gründete J. Pásztókai-Szeőke ihre Meinung? Bei Ovid, bei dem Webwettbewerb von Minerva und Arache gehören pecten und radius zum selben Gerätbestand. ${ }^{22} \mathrm{H}$. Blümner hat die Anwendungsweise des Gerätes missverstanden, aber es war für ihn klar, dass die Römer darunter einen aus Holz gefertigten, zugespitzten, nadelartigen Gegenstand verstanden haben. Auch ein nadelartiges Gerät, mit dem die Saiten gerührt wurden, wurde genauso genannt. ${ }^{23}$ Das weist darauf hin, dass das radius ein kurzes Gerät sein musste.

J. Pásztókai-Szeőke veröffentlichte mehrmals zwei für beweiskräftig gehaltene Grabsteine. An dem Grabstein der Severa Seleuciana ist ein stilisierter senkrechter Webstuhl mit zwei Walzen dargestellt. Daneben ist ein ebenso großer, nach unten zugespitzter Gegenstand zu sehen, dessen reales Maß wir nicht kennen. ${ }^{24} \mathrm{Am}$ Grabstein der Genetiva hielt eine Frau in der linken Hand eine angespulte Spindel, in der rechten Hand einen 20-30 cm langen, an einem Ende zugespitzten Gegenstand. ${ }^{25}$ Der Letztere könnte aufgrund der Maße dem zugespitzten Eisengerät aus Pannonien entsprechen, aber - wie schon erwähnt - hielten die Frauen immer Spindel und Spinnrocken in den Händen. Das radius gehört mit dem pecten zusammen, aber in der linken Hand von Genetiva ist kein Webkamm,

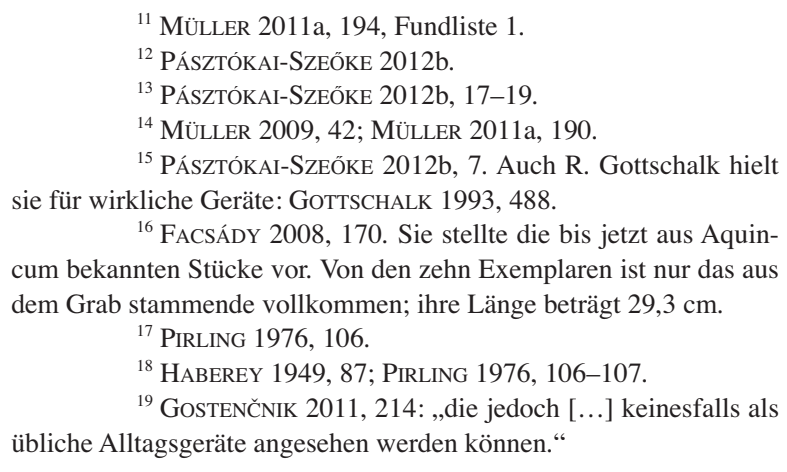

${ }^{19}$ GostenČNIK 2011, 214: „die jedoch [...] keinesfalls als übliche Alltagsgeräte angesehen werden können."

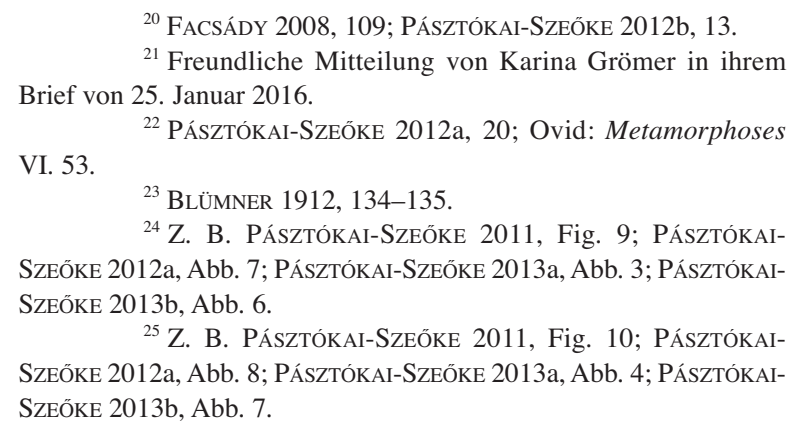

${ }^{20}$ FACSÁDY 2008, 109; PÁSZTÓKAI-SZEŐKE 2012b, 13.

${ }^{21}$ Freundliche Mitteilung von Karina Grömer in ihrem Brief von 25. Januar 2016.

${ }^{22}$ PÁszTóKAI-SZEŐKe 2012a, 20; Ovid: Metamorphoses VI. 53.

${ }^{23}$ BLÜMNER 1912, 134-135.

${ }^{24}$ Z. B. PÁsZtóKai-SZEŐKE 2011, Fig. 9; PÁsztóKaISZEŐKe 2012a, Abb. 7; PÁsZTÓKAI-SZEÖKe 2013a, Abb. 3; PÁSZTóKAISZEŐKE 2013b, Abb. 6.

${ }^{25}$ Z. B. PÁsZTóKaI-SzeỏKe 2011, Fig. 10; PÁszTóKaISZEÖKe 2012a, Abb. 8; PÁsZTóKAI-SZEÖKe 2013a, Abb. 4; PÁsZTóKAISZEÖKE 2013b, Abb. 7. 
sondern eine Spindel zu sehen. Diese Darstellung ist eigenartig, da die Frauen an den Grabsteinen - der Wirklichkeit entsprechend - den Spinnrocken in der Regel in der linken Hand hielten und am Ende ist immer das Werg zu sehen. Mit dem radius arbeiteten sie hingegen in der rechten Hand. Wenn dieses Gerät aber ein pinbeater (radius) war, wie das P. Walton Rogers in mehreren Werken behauptete, ${ }^{26}$ dann hat der Steinmetz das Gerät bewusst entstellt, damit es sichtbar wird. In richtigem Maßstab dargestellt hätte man nämlich von dem kaum 10-12 cm langen Gegenstand in der Hand der Genetiva nur die Spitze sehen können. J. PásztókaiSzeőke nannte dieses Gerät englisch pin-beater, sie hat aber keinen Gegenstand veröffentlicht. ${ }^{27}$

Im Internet habe ich zahlreiche pin-beaters gefunden, und zwar beide Varianten: Erstens diejenige, die nur an einem Ende zugespitzt sind $(A b b .1 . a)^{28}$ und am Webstuhl mit zwei Walzen benutzt wurden, zweitens die an beiden Enden zugespitzten (Abb. 1.b-c), die am Webstuhl mit Beschwerern benutzt wurden. ${ }^{29}$ Aufgrund der Maße sind alle 10-12 cm lang. In der Veröffentlichung von Baroness Kaleeb ist kein Maß neben den nur
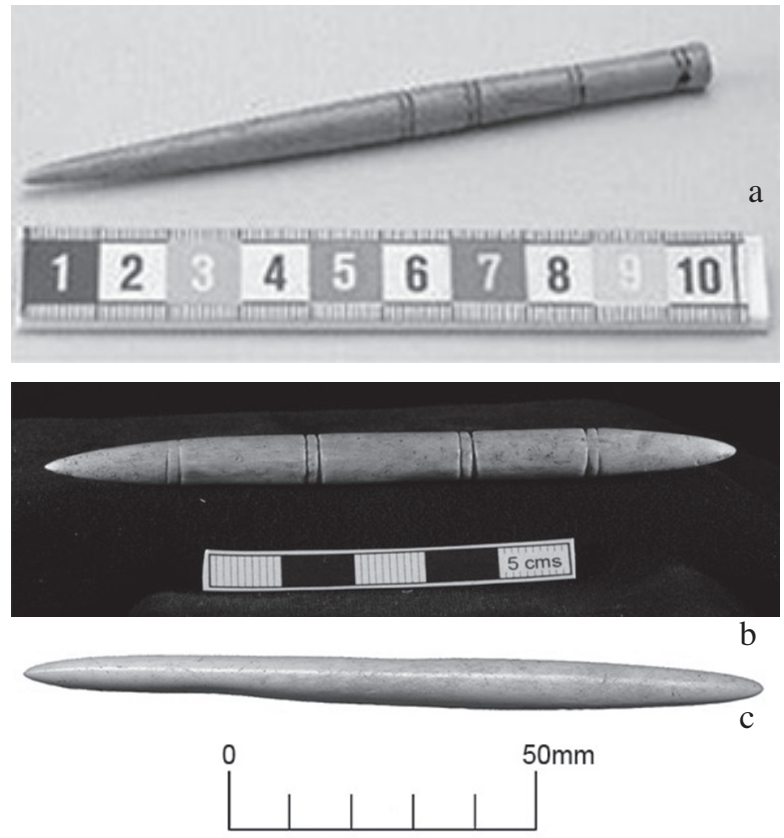

Abb. 1. Wikingische Fadenordner (pin-beaters) aus Knochen an einem Ende zugespitzten, angelsächsischen pin-beaters aus Bein (Abb. 2) angegeben, aber die Spinnwirtel daneben zeigen, dass auch diese nicht länger sein konnten. ${ }^{30}$ K. Gostenčnik erwähnte nur, dass die so genannten pin-beaters in der Römerzeit sowohl aus Holz als auch aus Knochen hergestellt wurden. ${ }^{31} \mathrm{M}$. T. Bíró bestimmte unter den römischen Knochengegenständen des Ungarischen Nationalmuseums die 7-12 cm langen, an beiden Enden zugespitzten Exemplare als pin-beaters. ${ }^{32}$ Auch der zweite Typ der pin-beaters konnte in Pannonien bekannt gewesen sein, diese konnten aber leicht mit den ebenfalls an einem Ende zugespitzten, einfachen Haarnadeln verwechselt werden, von denen wir zwei Varianten - eine 8-9 cm und eine $12-13 \mathrm{~cm}$ lange - kennen. ${ }^{33}$

Laut J. Pásztókai-Szeőke wird die Zusammengehörigkeit von radius und pecten auch dadurch bestätigt, dass sie in den Bestattungen des 4. Jahrhunderts gemeinsam vorkommen. Die Proportionen sind aber ganz verschieden. Von den 35 Webkämmen kamen nur fünf (14 \%) aus Gräbern zum Vorschein. ${ }^{34}$ Dagegen sind von den 163 zugespitzten Eisenstäben 111 Exemplare $(68 \%)$ aus 31 Gräberfeldern bekannt. ${ }^{35}$ Von den fünf Gräbern mit Webkamm enthielten vier auch zugespitzte Eisenstäbe. In zwei Fällen war auch ein Spinnwirtel zwischen den Beigaben. Aus Grab 2 von Zalaegerszeg-Kaszaháza kamen ebenfalls zugespitzter Eisenstab und Spinnwirtel aus Knochen gemeinsam hervor. ${ }^{36}$ Das gemeinsame Vorkommen des Webkamms und des zugespitzten Eisenstabes in den Frauengräbern kann nicht häufig genannt werden.

Aus dem archäologischen Material kennen wir also hauptsächlich aus Knochen hergestellte radius, diese sind aber wesentlich kleiner als die zugespitzten Eisenstäbe. Mit den 20-30 cm langen, dicken Eisenstäben hätte

${ }^{26}$ Die Werke von P. Walton Rogers konnte ich nicht besorgen. Nicht nur PÁszTóKAI-SzEỎKE 2012a beruft sich auf diese, sondern z. B. auch kaleeb.galtham.org/pdf/pinbeaters.pdf.

${ }^{27}$ Chr. Petty zeigt den Gebrauch des pin-beaters bei der Arbeit, dieses Gerät ist aber höchstens $10 \mathrm{~cm}$ lang (PETTY 2014, 74, Fig. 32).

${ }^{28}$ Viking refs: crafts and manufacturing (im Internet).

${ }^{29}$ Es ist vorstellbar, dass auch am Webstuhl mit Beschwerern die nur an einem Ende zugespitzten Geräte benutzt wurden. Im Archäologischen Museum in Ankara wird ein Grabstein aus Nahilan aufbewahrt, an dessen unterer Hälfte ein Webstuhl mit Beschwerern zu sehen ist. Oben, an der linken Seite des Webstuhls befinden sich zwei, an einem Ende zugespitzte Gegenstände (pin-beater), in der Mitte ein zweiseitiger Kamm, unten zwei Weberschiffchen. Ein weiterer Kamm mit Stiel wurde oberhalb des Webstuhls dargestellt (PetTy 2014, 30-31 und Fig. 9).

${ }^{30}$ kaleeb.galtham.org/pdf/pinbeaters.pdf aufgrund von HooK-MAcGregor 1997, 29.

${ }^{31}$ GOSTENČNIK 2011, 218.

${ }^{32}$ T. Bíró 1994, 102-103 und Taf. LXI.531-534.

${ }^{33}$ T. Bíró 1994, 31 und Taf. XII-XIV.99-137.

${ }^{34}$ PÁsZTÓKAI-SZEŐKe 2012a, 15-16.

${ }^{35}$ MÜLler 2011a, 190 und Fundortliste 1.

${ }^{36}$ MÜLLER 2014b. 


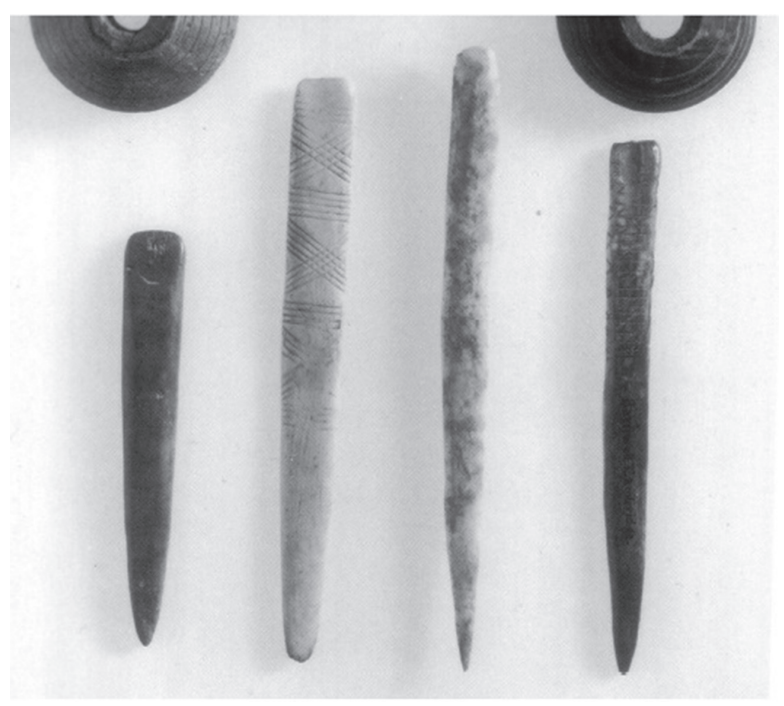

Abb. 2. Angelsächsische Fadenordner (pin-beaters) aus Knochen man nur schwerlich die dichten Kettenfäden ausheben oder ordnen können. Auch aus Metall konnten Nadeln zum Ordnen der Kettenfäden hergestellt werden. Zumindest wurde ein angelsächsisches, aus Bronze hergestelltes, zugespitztes Gerät mit gedrehtem Stiel aus dem 5.-7. Jahrhundert so bestimmt, das ebenfalls $10 \mathrm{~cm}$ lang ist (Abb. 3). ${ }^{37} \mathrm{~J}$. Pásztókai-Szeőke beruft sich darauf, dass im Nahen Osten frühere literarische Hinweise bekannt sind, in denen der pin-beater mit der Benennung „Nagel der Weber“ oder „Ahle der Weber“" vorkommt. ${ }^{38}$ Auch diese Benennung weist darauf hin, dass es sich um einen kürzeren Gegenstand handeln konnte.

Eine gute Bekannte, die Meisterin der Volkskunst ist die Weberin Frau Erika Bordácsné Kishonti in der Stadt Keszthely. Sie arbeitet auch mit senkrechtem Webstuhl mit zwei Walzen. Zum Ausheben oder zum Ordnen der Kettenfäden benutzt sie zwei Werkzeuge $(A b b .4)$. Das eine ist $15 \mathrm{~cm}$ lang: Das hat sie noch in den 1980er Jahren im Burda-Geschäft in Budapest ge-

kauft. Ein Ende ist durchlocht, deshalb ist es geeignet, auch an anderen Webstühlen verschiedene Probleme zu lösen. Das andere ist $12 \mathrm{~cm}$ lang und die Spitze ein wenig gekrümmt. Dieses wurde aus einer Fahrradspeiche hergestellt.

Der Handspinnrocken wurde am Anfang des 20. Jahrhunderts auf die Randgebiete Europas zurückgedrängt. ${ }^{39}$ Er wurde teilweise durch den Gürtelspinnrocken verdrängt. Darüber schrieb Lajos Szolnoky: „Ein noch rationellerer Gegenstand war zur Anbringung der Fasern der Gürtelspinnrocken. Es handelt sich um einen ungefähr $1 \mathrm{~m}$ langen Stab, dessen unteres Ende in den Gürtel gesteckt wurde. So wurde die (linke) Hand ganz für das Spinnen befreit. “40 Das müssen wir berücksichtigen in Zusammenhang mit dem Grab 111 aus Keszthely-Dobogó. In diesem Grab befanden sich nämlich neben dem eisernen Webkamm und dem gedrechselten Spinnwirtel aus Knochen auch zwei zugespitzte Eisenstäbe. ${ }^{41}$ Die zwei Eisenstäbe sind aber nicht gleich. Das stumpfe Ende von dem einem ist hohl, hier konnte ursprünglich ein Holzstiel befestigt gewesen sein. Tüllenartige Ausbildungen konnten an mehreren zugespitzten Eisenstäben beobachtet werden: z. B. Keszthely-Halászrét Grab 1, Keszthely-Dobogó Grab $5^{42}$ oder Zengővárkony II, die Gräber 12 und $14 .{ }^{43}$ Deshalb habe ich vorgeschlagen, es könnte sich um die Spitze von Gürtelspinnrocken handeln. ${ }^{44}$

J. Pásztókai-Szeőke wies auf einen Sarkophag aus Ostia hin, der für einen Schuster gestellt wurde. An der rechten Seite des Reliefs, das die Werkstatt darstellt, ist der Lehrling zu sehen, der aus einer längeren Faser Faden zum Nähen der Schuhe spinnt. Der Spinnrocken ist in seinen Gürtel gesteckt. ${ }^{45}$ Das ist aber eine falsche Interpretation. Am Relief wurde kein Spinnrocken dargestellt. Aller Wahrscheinlichkeit nach wurde hier ein Seiler verewigt (Abb. 5). ${ }^{46}$ Am Omphale-Mosaik des Kapitolischen Museums wurde tatsächlich ein Gürtelspinnrocken dargestellt, da Herkules hier mit einem in seinen Gürtel gesteckten Spinnrocken spinnt (Abb. 6). ${ }^{47}$ In das Grab 111 von Keszthely-Dobogó wurden also ein Hand- bzw. ein Gürtelspinnrocken gelegt, vermutlich deshalb, weil mit den zwei Geräten verschiedene Materialien gesponnen wurden.

Zusammenfassend kann also festgestellt werden, dass die 20-30 cm langen, an einem Ende zugespitzten Eisenstäbe keine Geräte zum Ausheben oder zum Ordnen der Kettenfäden an dem senkrechten Webstuhl mit zwei

${ }^{37}$ Flickriver.daegrad tools's... (im Internet).

${ }^{38}$ PÁsZTóKAI-SzEÖKe 2012a, 20.

${ }^{39}$ SZOLNOKY 1991, 356.

${ }^{40}$ SZOLNOKY 1991, 356-357.

${ }^{41}$ SÁGi 1981, 103 und 76, Abb. 57. Die Bedeutung des Grabes zeigt, dass auch J. Pásztókai-Szeőke die Funde vorstellte (PÁSZTÓKAI-SZEŐKE 2013b, 262, Abb. 10).

${ }^{42}$ SÁGi 1960, 190 und 208.

${ }^{43}$ Dombay 1957, 289.

${ }^{44}$ MÜLLER 2009, 44; MüLler 2011a, 188.
${ }^{45}$ PÁsZTÓKAI-SZEỎKe 2012b. 12.

${ }^{46}$ Laut der griechischen Inschrift wurde das Grabmal von L. Atilius Artemas seinem Freund Titus Flavius Trophimas gestellt. An der rechten Seite unterhalten sich die Freunde. Die Szene an der linken Seite zeigt den Schuster bei der Arbeit. Rechts von ihm zieht ein Mann - der Freund - aus einem größeren Hanfknoten einen dickeren Faden und wickelt ihn auf einen Stab. Der Freund wurde als Seiler bestimmt (ZiMMER 1982, 132-133, Kat. 47; ZiMMER 1985, 209; ÖZER 2009, 28). 1994, 49).

${ }^{47}$ Umgezeichnet veröffentlicht von M. T. Bíró (T. Bíró 


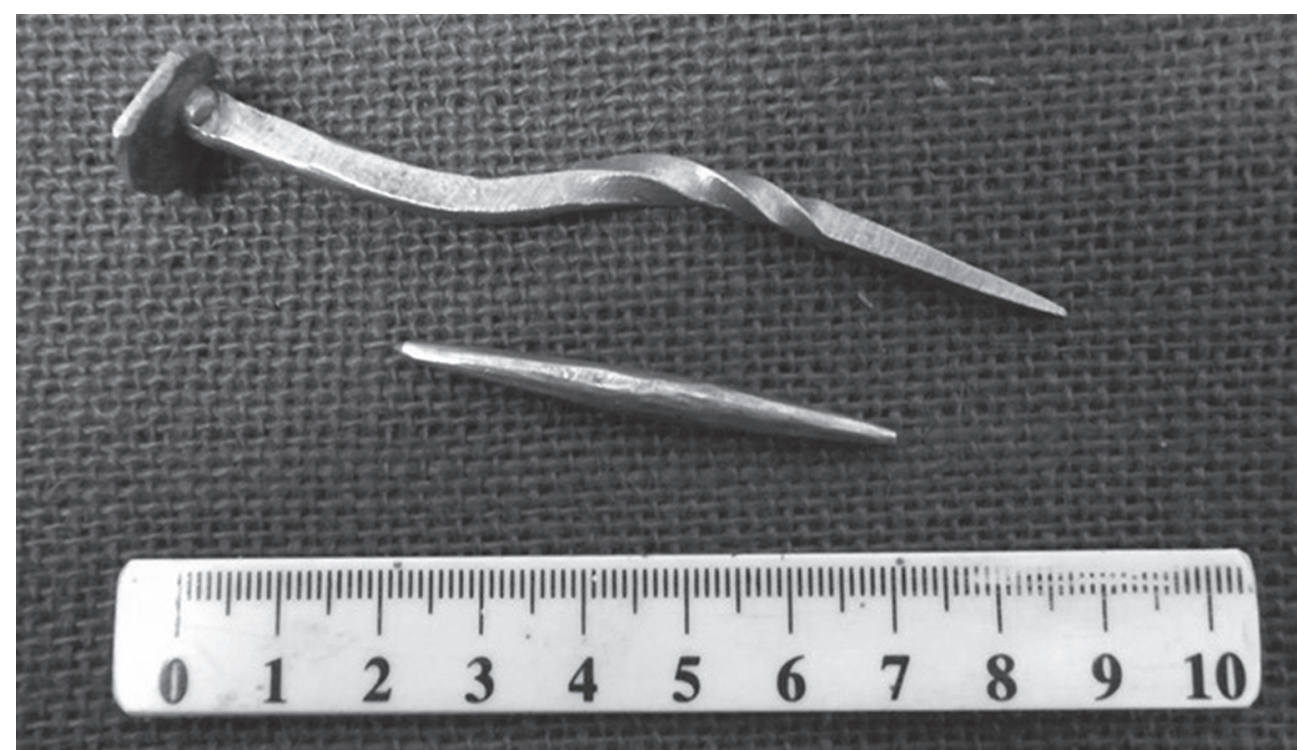

Abb. 3. Angelsächsische Fadenordner (pin-beaters) aus Metall

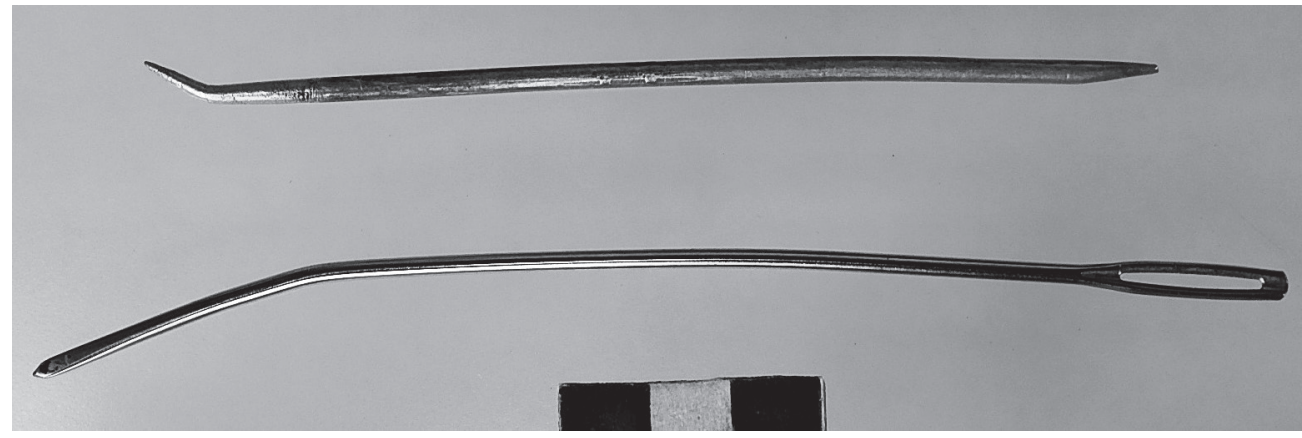

Abb. 4. Die Fadenordner von Erika Bordácsné Kishont

Walzen (radius, pin-beater) waren, sondern Spinnrocken, die lateinisch colus genannt wurden, und zwar die massiven Hand- und die hohlen Gürtelspinnrocken.

Aus den Tatsachen, dass laut Aurelius Victor Kaiser Galerius 292 in Pannonien Wälder rodete bzw. das Wasser des Balaton (lacus Pelso) in die Donau ableitete, ${ }^{48}$ dann die Karpen ansiedelte, weiters daraus, dass die datierbaren Exemplare von pecten und radius im 4. Jahrhundert hergestellt wurden und in erster Linie aus dem südlichen Transdanubien bekannt sind, ${ }^{49}$ zog J. Pásztókai-Szeőke weitgehende Schlüsse. Es ist wahr, dass die Webkämme und die zugespitzten eisernen Spinnrocken hauptsächlich aus ländlichen Siedlungen stammen bzw. aus den Innenbefestigungen und auch Agrargeräte beinhaltenden Funden bekannt und für städtische Siedlungen und ihre Gräberfelder überhaupt nicht kennzeichnend sind. ${ }^{50}$ Daraus schloss J. Pásztókai-Szeőke das Folgende: All diese Tatsachen waren Teile eines großzügigen, mehrere Jahrzehnte dauernden, gezielten Regierungsplans, mit dem ,in die ungünstigen bzw. weniger günstigen südpannonischen Naturverhältnisse eingreifend man die örtliche Agrarproduktivität steigern wollte“ ${ }^{51} \mathrm{Zu}$ den Ergebnissen gehören die ohne Vorereignisse, nach einheitlichen Plänen erbau-

48 „pauloque post vulnere pestilenti con sumptus est, cum agrum satis reipublicae commodantem caesis immanibus silvis atque emissio in Danubiam lacu Pelsone apud Pannonios fecisset. Cuius gratia provinciam uxoris nomine Valeriam appelavit." Sextus Aurelius Victor: De Caesaribus 40, 9-10.

${ }^{49}$ PÁsztóKai-SzeŐKe 2012a, 21, Abb. 11; PÁszTÓKaISZEŐKE-SERLEGI 2013, Abb. 3.
${ }^{50}$ PÁSZTÓKAI-SzEŌKe 2012b, 20, Abb, 11; PÁSzTÓKAISzEŐKE-SERLEGI 2013, 69. Es kann bemerkt werden, dass unlängst eben aus Savaria ein eiserner Handspinnrocken veröffentlicht wurde (BALÁZS 2015, 281, Kat. 25.4).

${ }^{51}$ PÁsZTÓKAI-SzEŐKe-SERLEGI 2013, 71. 


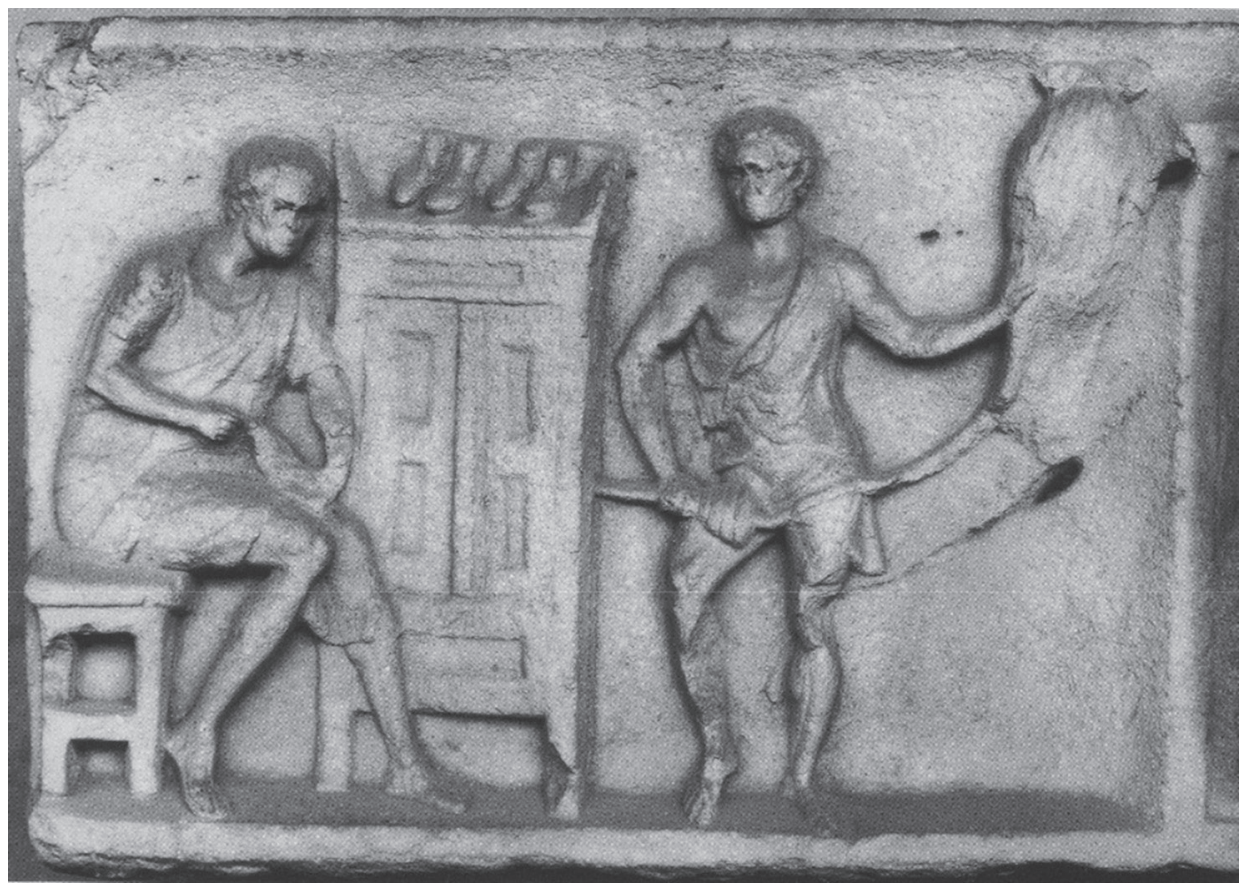

Abb. 5. Der Grabstein des Titus Flavius Trophimas, Detail

ten Innenbefestigungen. Diese waren aufgrund der in ihnen befindlichen riesigen horrea die Sammel-, Speicher- und Neuverteilerzentren der örtlichen Agrarmehrbeträge. ${ }^{52}$ Die Überschüsse, die die Bedürfnisse der Provinz übertrafen, wurden am Wasserweg in andere Provinzen des Reichs transportiert. Nachher - zusammen mit Gábor Serlegi - hat J. Pásztókai-Szeőke auch die Art und Weise des Ablassens des Balaton und dessen archäologische Beweise vorgeführt. ${ }^{53}$ Ihre Vorstellungen wurden auch von anderen übernommen. ${ }^{54}$ Im Folgenden möchten wir die einzelnen Elemente dieser Konzeption und ihre Verlässlichkeit überprüfen.

Die Exemplare der beiden Eisengeräte - unabhängig davon, dass der zugespitzte Eisenstab nicht beim Weben, sondern beim Spinnen benutzt wurde - wurden im 4. Jahrhundert hergestellt. Über die Webkämme hat J. Pásztókai-Szeőke angenommen, dass die frühesten Stücke vielleicht schon im 2.-3. Jahrhundert erzeugt wurden. ${ }^{55}$ Die Dichte der Zähne der Webkämme ist verschieden: ${ }^{56}$ Bei den von mir untersuchten Stücken waren die Werte zwischen 3,8 mm und 5,5 mm. ${ }^{57}$ Darin hat J. Pásztókai-Szeőke vollkommen Recht, dass man mit diesen 20-30 cm langen, mit kurzen Zähnen versehenen Kämmen keine Knüpfteppiche oder Gewebe mit kompliziertem Muster weben konnte. Sie betonte aber auch, dass sie nicht nur zum Weben von Gewebe mit niedriger Fadendichte geeignet waren ${ }^{58}$ man konnte also nicht nur Sacktücher mit ihnen weben. Sie kommen in städtischer Umgebung vielleicht deshalb seltener vor, weil die einfacheren Gewebe ohne Muster die Hausfrauen in den ländlichen Gebieten selber webten. Nach den Quellen wurde der Handrocken übrigens aus organischem Material, aus Holz oder Schilf, hergestellt, ${ }^{59}$ so blieb davon bei unseren geographischen Verhältnissen keine Spur erhalten. Auch die Webkämme konnten hauptsächlich mit eisernen Zähnen versehene Holzgeräte sein oder sie wurden aus Knochen hergestellt. ${ }^{60}$ Es kann also nicht mit Sicherheit behauptet werden, dass sich die Zahl der Webkämme und der Handspinnrocken im 4. Jahr-

${ }^{52}$ PÁsZTÓKAI-SZEŐKe 2012a, 20-21; PÁSZTÓKAI-SZEŐKE 2013a, 212-213; PÁsZTóKAI-SZEŐKE 2013b, 261; PÁsZTÓKAI-SZEŐKESERLEGI 2013, 70-71. SERLEGI 2014

${ }^{53}$ PÁsZTóKAI-SZEŌKE-SERLEGI2013; PÁsZTÓKAI-SZEŐKE-

${ }^{54}$ VAJDA 2014

${ }^{55}$ PÁSZTÓKAI-SZEŐKe 2010, 251; PÁSZTÓKAI-SZEŐKE-SERLEGI 2013, 68. Die von J. Henning veröffentlichten Exemplare aus Dazien wurden aller Wahrscheinlichkeit nach vor dem 4. Jahrhundert hergestellt (HenNing 1987, Taf. 54, Typ Q1).
${ }^{56}$ PÁszTóKaI-SzEỏKe-Serlegi 2013, 68; im Allgemeinen ein oder zwei kurze Zähne pro Zentimeter.

${ }^{57}$ MÜller 1982, 532; MÜLler 1994, 183.

${ }^{58}$ PÁSZTÓKAI-SZEŌKe 2012a, 20; PÁSZTÓKAI-SZEŌKE-SERLEGI 2013, 68 .

${ }^{59}$ BLÜMNER 1912, 109-110.

${ }^{60}$ Z. B. T. BÍRÓ 1994, Plate LXIII.541. Auch heutzutage werden Webkämme (oder Webgabel) ganz aus Holz hergestellt (LANDGRAF-SZITTNER 1984, 57). 
hundert plötzlich erhöhte. Es ist vorstellbar, dass diese Geräte in der Spätkaiserzeit auch aus Eisen hergestellt wurden und in Südtransdanubien sich die Sitte verbreitete, diese Werkzeuge als Beigabe in die Gräber zu legen. Übrigens kennen wir auch außerhalb von Pannonien solche zugespitzte Eisenstäbe mit kreisförmigem Durchschnitt, diese wurden aber als Spitzmeißel oder Durchschlag bestimmt. ${ }^{61}$ Das Produktionsniveau des Eisens war in Pannonien ziemlich hoch und eben in der Spätkaiserzeit verbreiteten sich die aus Eisen hergestellten Varianten von vielen Geräten. Als Beispiel können wir die Pflugketten erwähnen, die den Gebrauch des Pflugkarrens beweisen. Aus Eisen hergestellt kennen wir sie nur aus Pannonien und aus der unmittelbaren Umgebung. ${ }^{62}$ Das bedeutet nicht, dass an anderen Gebieten des Reichs der schwere Pflug mit Pflugkarren unbekannt war. Dort wurde der Grindel jedoch mit einem Lederband oder mit Wiedel aus organischem Material zum Pflugkarren befestigt und von denen blieb genauso keine Spur erhalten, wie von den hölzernen Handspinnrocken und Webkämmen.

Es ist bis heute umstritten, wie hoch das Wasserniveau des Balaton in der Römerzeit war und inwieweit es durch die Tätigkeit von Kaiser Galerius beeinflusst wurde. Die frühere Literatur machte im Allgemeinen keinen Unterschied zwischen dem Wasserstand der Früh- und der Spätkaiserzeit. Árpád Virág zum Beispiel vertrat die Meinung, dass in der Römerzeit „das Wasser des Sees durch eine längere Periode sogar um einen Meter niedrigeres Niveau haben konnte als heute "63 bzw. der Wasserstand in der Römerzeit zwischen 103,8 m und 104,8 m über der Adria schwankte. ${ }^{64}$ Lange war es umstritten, wie alt die Mauerreste sind, die in Siófok bei dem Bau der Eisenbahn nach Kaposvár zum Vorschein kamen und die von Bálint Kuzsinszky ${ }^{65}$ als Überreste der während der Wasserregulierungsarbeiten des Galerius erbauten Schleuse bestimmt wurden. Die verschiedenen Interpretationen legte Árpád Virág detailliert dar. ${ }^{66}$ Seine Konklusion war: Die Römer haben keine Schleuse gebaut.

Der Bericht von Aurelius Victor wurde verschiedenartig erklärt. ${ }^{67}$ Heute ist die Forschung darin schon einig, dass der Wasserstand in der Frühkaiserzeit in Folge des niederschlagarmen und warmen Klimas niedrig

${ }^{61}$ Außer den von J. Pásztókai-Szeőke erwähnten und von mir aufgezählten Beispielen (MüLLER 2009, 44) kennen wir sie zum Beispiel aus der spätantiken Höhensiedlung Duell in Kärnten, wo neben 29 Spinnwirteln aus Knochen oder Ton auch noch sechs 23-25 cm lange, zugespitzte Eisenstäbe gefunden und als Durchschläge bestimmt wurden (STEINKLAUBER 2013, Taf. 97 [D 11], 104 [D 94], 120 [D 225], 125 [D 261], 132 [D 318] und 135 [D 349]). R. Gottschalk erwähnte solche Eisenstäbe aus Spanien (GoTTSCHALK 1993, 486). Auch an der französischen Seite der Pyrenäen kamen eiserne Handspinnrocken in einem großen Eisengerätfund zum Vorschein, und zwar mit eisernen Webkämmen zusammen (MARICHAL 2000, Fig. 6, 15-18 und 147, die Handspinnrocken als Spitzmeißel, Fig. 15, 94-95, Fig. 16, 96, 100 und 161-162, die Webkämme als Kratzer bestimmt).

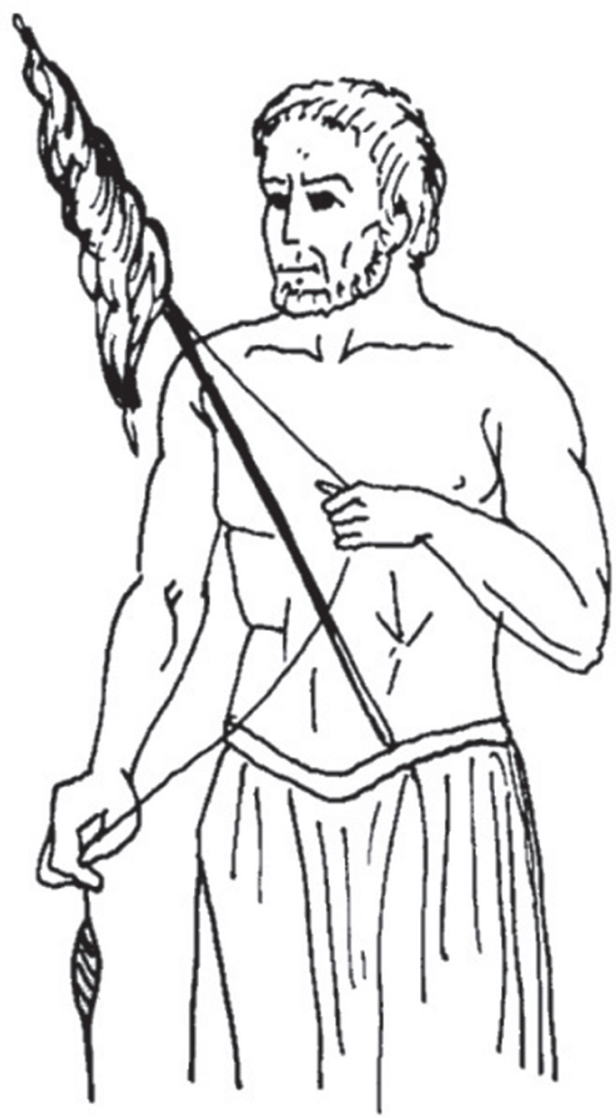

Abb. 6. Herkules mit Gürtelspinnrocken (nach T. Bíró 1994) 


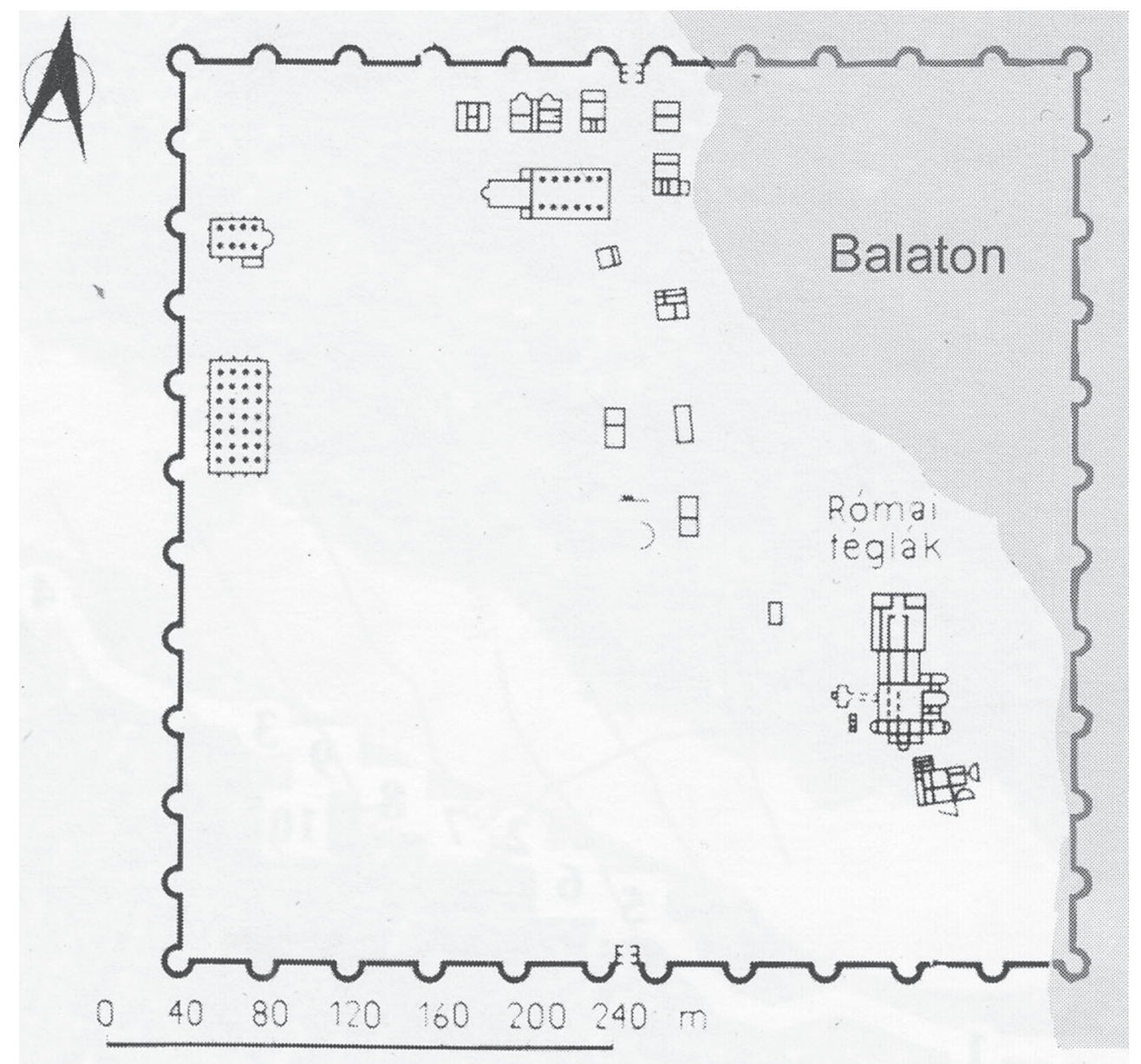

Abb. 7. Die Lage der Befestigung von Fenékpuszta (nach SERLEGI 2007)

war, ${ }^{68}$ dann der Wasserstand des Sees sich während des 3. Jahrhunderts wegen des feuchten und kühlen Klimas erhöhte. Es stellt sich die Frage, warum Galerius mit den Wasserregulierungsarbeiten anfing. Der erhöhte Wasserstand gefährdete vielleicht die Siedlungen und die Ackerfelder am Seeufer oder er wollte - der oben geschilderten Konzeption entsprechend - die Agrarproduktion steigern und dazu mit der bedeutenden Senkung des Wasserstandes des Balaton neue Ackerfelder gewinnen. Es wurde im Allgemeinen angenommen, dass der Kaiser sich mit der Eröffnung und dem Reinhalten der Sió-Mündung, mit dem Abbau der aus der gestauten Anschwemmung entstandenen „Sperre“ zwischen Siójut und Siómaros ${ }^{69}$ - also mit der Verhinderung des weiteren Ansteigens des Wasserniveaus- zufriedengab.

Pál Sümegi und seine Mitarbeiter haben an der Strecke des M7 Autobahnbaues im Komitat Somogy umweltarchäologische Untersuchungen vorgenommen und festgestellt, dass der Wasserstand von 102-103 m über dem Baltischen Meer des 2.-3. Jahrhunderts sich im 5.-6. Jahrhundert bis 104-105 m erhöhte. Sie gaben dazu drei Erklärungen. 1. Die Römer regelten das Balaton, aber in der Völkerwanderungszeit wurde das Wasserableitungssystem vernachlässigt und deshalb stieg das Wasser an. 2. Die Römer regelten das Balaton nicht, in Folge des warmen und trockenen Klimazyklus sank sich das Wasser. 3. Trotz der römischen Regelung sank sich der Wasserstand in Folge des warmen und trockenen Klimas; danach stieg aber der Wasserstand wegen der Vernachlässigung des Wasserableitungssystems und der Zunahme des Niederschlags. ${ }^{70}$

Gábor Serlegi fertigte aufgrund des orographischen Modells eine Wasserüberdeckungskarte und bewies, dass bei einem Wasserstand von 105 m über dem Baltischen Meer das Sió-Tal eine Bucht mit offenem Wasser

${ }^{69}$ VIRÁG 1998, 364-379, besonders 378-379.

${ }^{70}$ SÜMEGI et al. 2007, 252-253. 


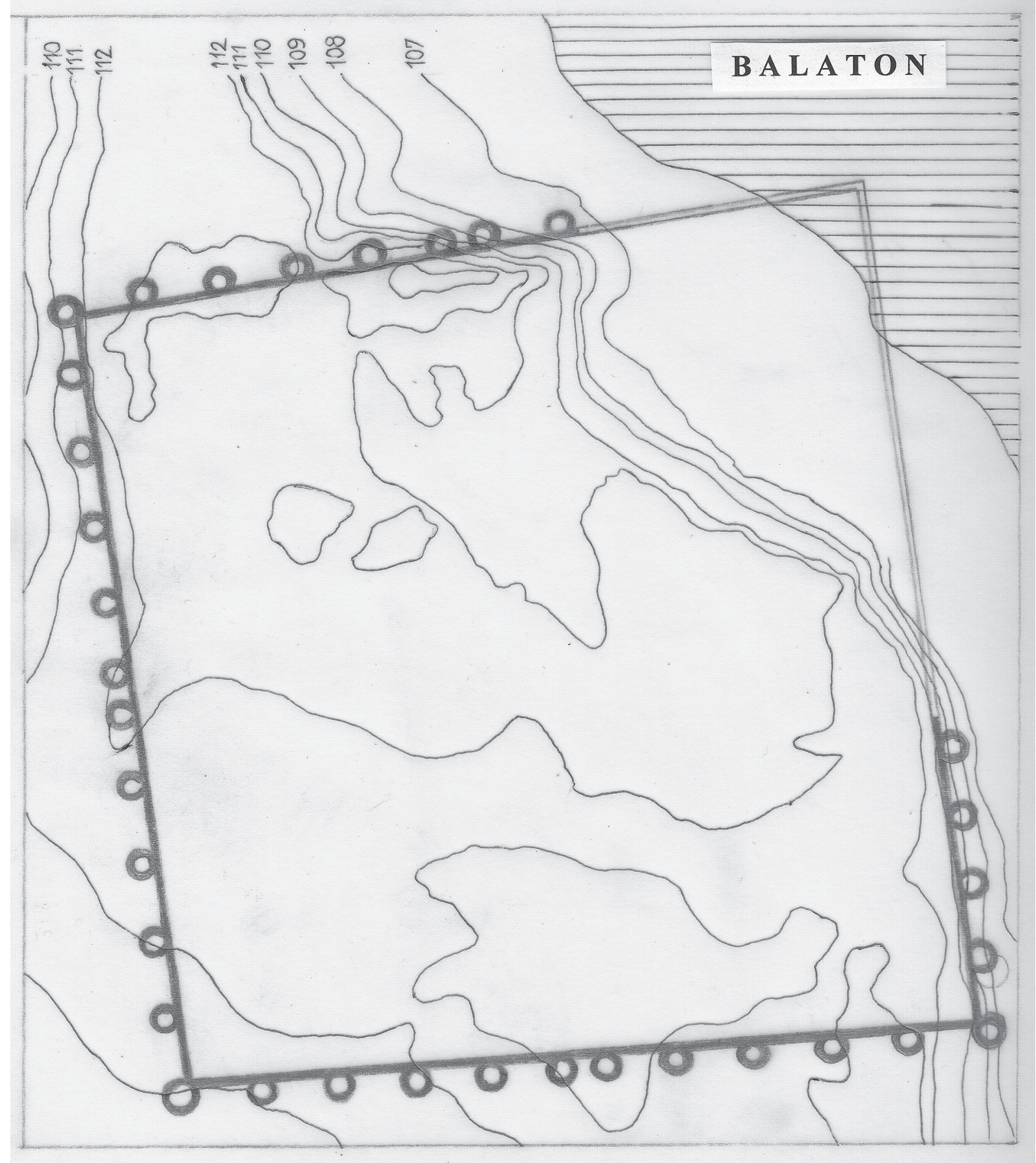

Abb. 8. Die Schichtlinien der Befestigung von Fenékpuszta (Rekonstruktion nach SÁGI 1989)

wurde. Die Stelle des Eingriffs von 292 konnte also beim Endpunkt der Bucht bei Szabadhídvég und Mezőkomárom gewesen sein. ${ }^{71}$ In der Studie, die er mit J. Pásztókai-Szeőke gemeinsam schrieb, geht er noch weiter und stellt fest, dass das Balaton und die Bächer Kis-Koppány und Jaba zu einem separaten Zuflussgebiet gehörten, was nichts mit dem Kapos-Koppány-Sárvíz-Donau Flussnetz zu tun hatte. Im Jahr 292 hat Kaiser Galerius mit einem 1,5 km

${ }^{71}$ SeRLEGi 2007, 305-306. 


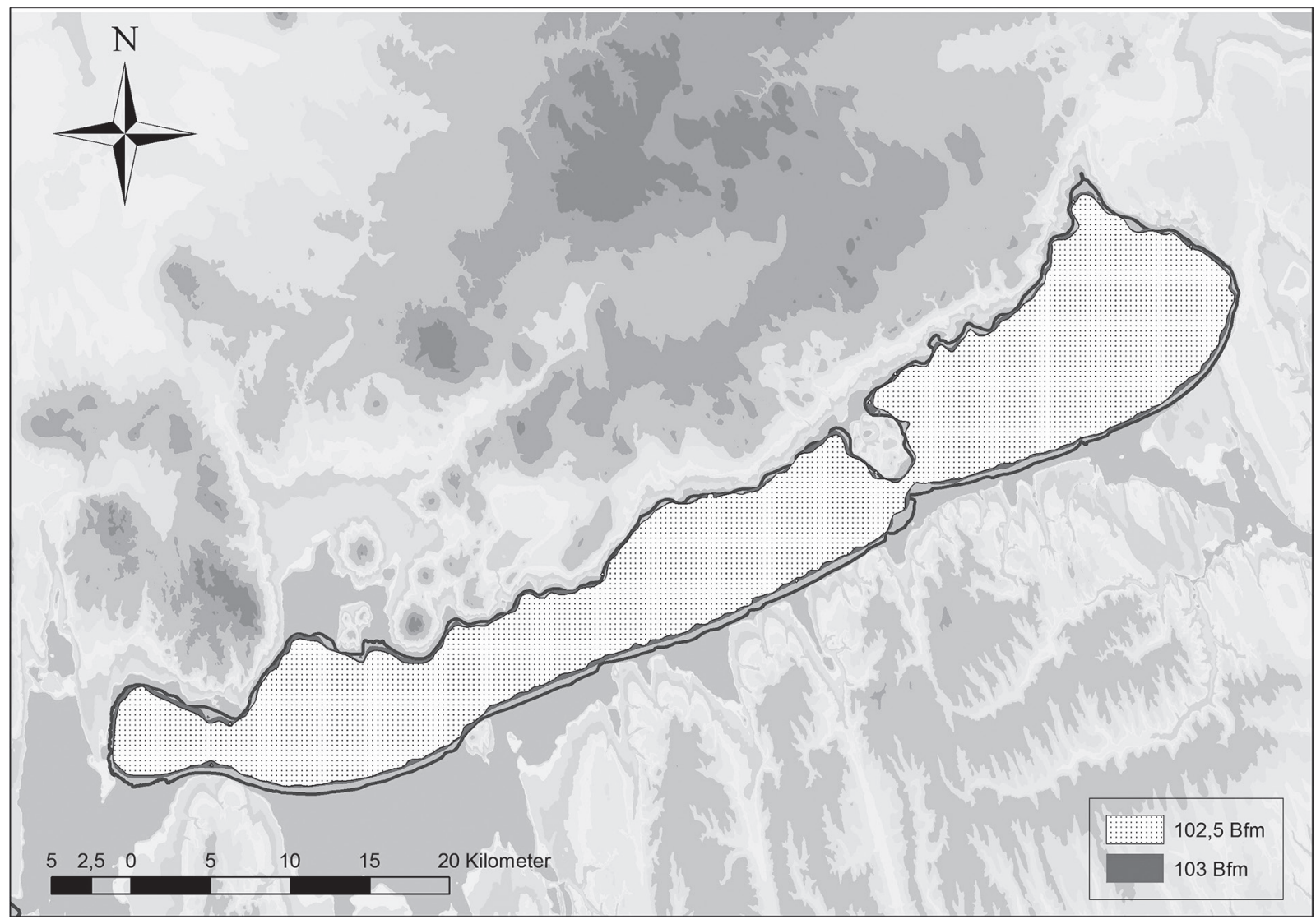

Abb. 9. Die Ausdehnung des Balaton bei 103 m und 102,5 m ü. M. (Entwurf von Bálint Havasi)

langen Durchschlag in Richtung des Baches Csíkgát die zwei Flussnetze zusammengebunden und so entstand die Verbindung zwischen dem Balaton und der Donau. ${ }^{72}$ So konnte das Wasserniveau des Balaton von $105 \mathrm{~m}$ über dem Baltischen Meer im 3. Jahrhundert bedeutend gesenkt werden. Der bedeutende Rückgang des Wasserstandes konnte nur das Ergebnis menschlichen Eingriffs gewesen sein, weil die Wasserschwankung der schweizerischen Seen in Einklang mit den klimatischen Trends der nördlichen Erdhälfte stand. Der Wasserstand des Bodensees war infolge des kühlen, feuchten Klimas in der zweiten Hälfte des 4. Jahrhunderts höher als heute. Der Wasserstand des Balaton sank dagegen, ${ }^{73}$ was auch die Angaben von zwei archäologischen Fundorten beweisen. ${ }^{74}$

Der erste Fundort ist die spätrömische Befestigung von Keszthely-Fenékpuszta, die im 4. Jahrhundert erbaut wurde. Gábor Serlegi veröffentlichte die Karte der Ungarischen Archäologischen Topographie, an der gut zu sehen ist, dass an der Stelle des NO-Teiles der Befestigung heute Wasser steht (Abb. 7). ${ }^{75}$ Daraus schließt er, dass die Römer nie ans Wasser bauten, der Wasserstand im 4. Jahrhundert also wesentlich niedriger als heute gewesen sein musste. ${ }^{76}$ Károly Sági veröffentlichte auch eine Befestigungskarte mit Höhenlinien. ${ }^{77}$ Die Befestigung wurde aber falsch eingetragen, ${ }^{78}$ sie befindet sich mindestens 30 m südlicher. Eine verlässliche Rekonstruktion zeigt $A b b .8$.

Vilmos Lipp leitete zuerst 1883 eine Ausgrabung in Fenékpuszta. Aus seiner Zusammenfassung ${ }^{79}$ stellt sich heraus, dass er 1859, als der Wasserstand des Sees besonders niedrig war - und auch nach der Schleuseneröffnung des Sió-Kanals 1863, als der Wasserstand stark gesenkt wurde -, vor der Befestigung, im Schlamm einge-

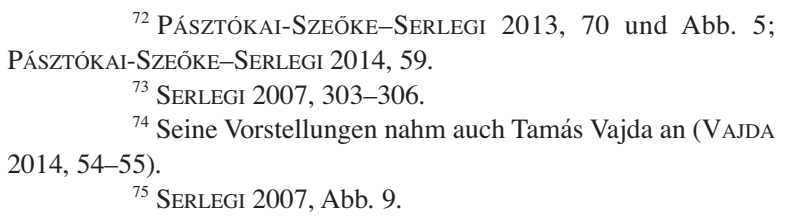

${ }^{75}$ SeRLEGi 2007, Abb. 9.

${ }^{76}$ PÁsztókai-SZEŐKe-SerLegi 2013, 70.

${ }^{77}$ SÁGI 1989, 265, Abb. 3.

${ }^{78}$ Laut dieser Karte befindet sich das Nordtor zwischen 107 und 108 m über der Adria und die steile Uferwand ist südlich von der Nordmauer.

${ }^{79}$ LIPP $1886,39-42$. 
stürzte Ziegelgräber beobachten könnte. In den Suchgräben, die er am flachen Ufer eröffnete, fand er nicht die Fortsetzung des Gräberfeldes bzw. er konnte nur ärmliche Bestattungen erschließen. Deshalb setzte er die Forschung am höher liegenden Gelände fort. Die heutige Uferwand entspricht am SO-Teil der Befestigung noch den Umständen der Römerzeit, da wir 2002 den S-Teil des Turmes Ost3 erschlossen haben und feststellen konnten, dass wegen der Senkung der Oberfläche die Fundamentierung des sich der Mauer anschließenden Turmes tiefer als die der O-Mauer war. ${ }^{80}$ Als 1888 die Eisenbahn zwischen Balatonszentgyörgy und Keszthely gebaut wurde, fand man hier, vor der Befestigungsmauer, am flachen Gelände spätrömische Bestattungen. Ein Teil von diesen haben wir 2002 wieder entdeckt. Vielleicht hat auch Lipp seine Suchgräben hier eröffnet? Am NO-Teil der Befestigung hätte er im Schlamm keine eingestürzten Ziegelgräber sehen können, da diese dann im Inneren der Befestigung gewesen wären. 1983, als der Amphora Leichttaucher Sportklub in Zusammenarbeit mit der Agraruniversität im seichten Uferwasser Schilfrhizomforschung unternahm, wurde auch in der Linie der N-Mauer der Schlamm herausgepumpt. Ich bekam die Möglichkeit zu tauchen und ich konnte feststellen, dass keine Mauerruinen in der Linie der N-Mauer der Befestigung zu finden sind. Wenn die Römer bei einem niedrigeren Wasserstand als heute gebaut hätten, dann müssten die Spuren im Wasser bis heute zu finden sein, da in den späteren Jahrhunderten, bei höherem Wasserstand hätte man die Steine nicht abbauen können.

Es gelang des Weiteren, eine missverständliche Angabe zu klären. Flóris Rómer besuchte Fenékpuszta 1861, als der Wasserstand noch niedrig war. An seiner Karte über Fenékpuszta markierte er im Wasser einen „Steinsarg“ ${ }^{81}$ Das könnte die Beobachtungen von Lipp bestätigen. 1983 haben wir auch den „Steinsarg“ gefunden. Es handelt sich um eine Sandsteinbank mit abgerundeten Ecken, etwa $80 \mathrm{~m}$ vom Ufer entfernt, mit ca. $70 \mathrm{~cm}$ Wasser bedeckt. Der NO-Teil der Befestigung wurde im 16.-17. Jahrhundert, als in Zusammenhang mit der europäischen Kleineisenzeit das Wasserniveau extrem hoch war, durch das Balaton weggeschwemmt.

Wir wissen nicht, wo das ursprüngliche römerzeitliche Ufer sich befand. Laut László Bendefy muss man mindestens mit der Wegschwemmung von 400-500 m rechnen. ${ }^{82}$ Árpád Virág schätzte dies ,,nur“ auf 200-300 m. ${ }^{83}$ Für die Wegschwemmung des Ufers bei Fenékpuszta haben wir auch einen Ausgrabungsbeweis. Östlich von der Hauptstraße 71, vor der N-Mauer der Befestigung, senkt sich die Uferwand steil. 1971 haben wir das N-Tor der Befestigung erschlossen. Vor dem Tor war die Uferwand $4 \mathrm{~m}$ hoch. Aus der Fundamentierung des im Mittelalter abgebauten westlichen, runden Torturms blieb an der Innenseite nur ein dreieckförmiger Teil erhalten. (Die Sohle befand sich 111,20 m über der Adria.) Die Sohle des Außenteils der Turmmauer fällt also über die heutige Oberfläche. ${ }^{84}$ Zur Zeit des Baus der Befestigung war der Wasserstand aller Wahrscheinlichkeit nach etwas höher als heute. Wenn Gábor Serlegi Recht hätte, dann sollte der Wasserstand im 4. Jahrhundert - in Betracht ziehend, dass das Wasser an der Stelle des NO-Eckturmes heute $70 \mathrm{~cm}$ tief ist und die Fundamente der Befestigungsmauer etwa $1 \mathrm{~m}$ tief waren, ${ }^{85}$ des Weiteren auch mit der Kapillarität rechnend - mindestens $1,5 \mathrm{~m}$, aber eher $2 \mathrm{~m}$ tiefer als heute gewesen sein. Die Bodenverhältnisse des Balaton in der Spätrömerzeit kennen wir nicht, aber die Ausdehnung des Sees war bestimmt wesentlich kleiner als heute, besonders entlang des seichten Südufers (Abb. 9). ${ }^{86}$

Für die Wegschwemmung des Balatonufers haben wir auch ein weiteres Beispiel. Balatonföldvár bekam seinen Namen vom keltischen Erdwall, dessen Überreste B. Kuzsinszky an der vergangenen Jahrhundertwende vermaß. Damals konnte nur mehr der SO-Rand dokumentiert werden, davor befanden sich die steile Uferwand und das flache Ufergelände (Abb. 10). Heute ist das Gelände fast völlig bebaut. ${ }^{87}$

Gábor Serlegi war der Meinung, dass die Wasserregulierungstätigkeit des Galerius sich auf die Aushebung eines 1,5 km langen Kanals beschränkte, mit dem er - im Fall „der Ausdehnung des Balaton im Naturzustand“ - die mit Wasser bedeckte Sió-Bucht mit dem Csíkgát-Bach verband und dadurch auch das Balaton mit der Donau. Die Wasserüberdeckungskarte zeigt, dass diese Bucht nur bei einem Wasserniveau von 105 m über dem Baltikum mit

${ }^{80}$ MÜLLER 2011b, 239-243.

${ }^{81}$ RÓMER 1862, 39.

${ }^{82}$ BENDEFY-V. NAGY 1969.

${ }^{83}$ VIRÁG 1998, 362.

${ }^{84}$ MÜLLER 1979, 138-139.

${ }^{85}$ Die Sohle der N-Mauer erreichten wir 111,22 m bzw. 111,27 m über der Adria, 1,5-2,2 m unter der heutigen Oberfläche und in 90-110 cm Tiefe vom untersten Gehniveau (MÜLLER 1979, 124125). Die Sohle der O-Mauer der Befestigung erreichten wir beim
Turm O3 1,5 m unter der heutigen Oberfläche, 107,67 m über dem Baltikum (MÜLLER 2011b, 240).

${ }^{86}$ Ich bedanke mich bei Herrn Bálint Havasi, der für mich diese Karte verfertigte. Der genehmigte höchste Stand des Balaton ist am Wasserpegel bei Siófok bei $110 \mathrm{~cm}$ festgelegt. Das entspricht $104,52 \mathrm{~m}$ über dem Baltischen Meer, der Wasserstand hätte also bei 103 m bzw. 102,5 m über dem Baltikum sein sollen. Am Südufer war der See an manchen Stellen mehr als $700 \mathrm{~m}$ schmäler als heute.

${ }^{87}$ NovÁKI 2006, 135, Abb. 10. 


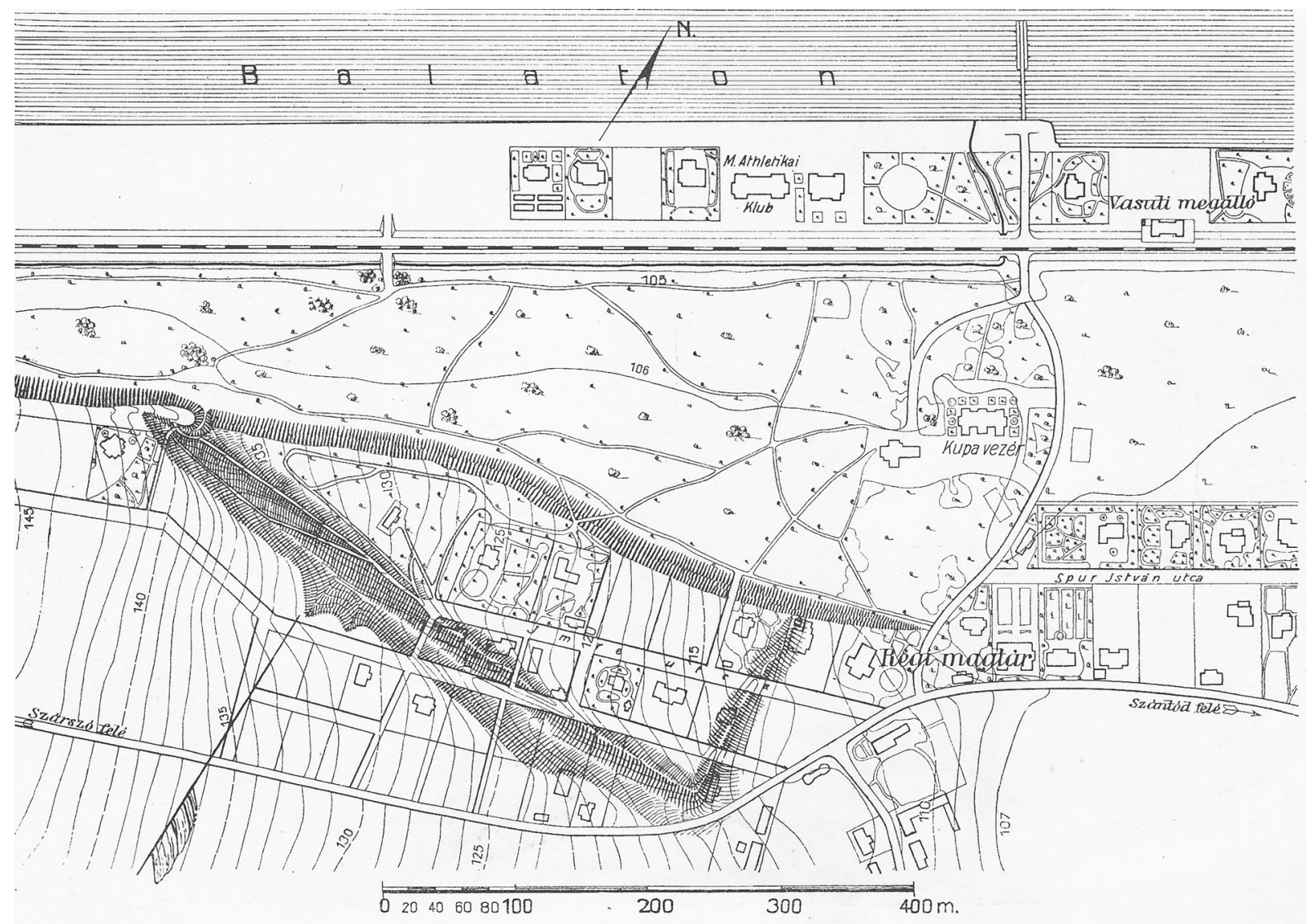

Abb. 10. Die Reste des keltischen Erdwalls bei Balatonföldvár am Anfang des 20. Jahrhunderts (nach KUZSINSZKY 1920)

Unlängst fasste Péter Kovács die Quellen über die Ansiedlung der Karpen zusammen. Seiner Meinung nach konnte die Ansiedlung der Karpen in den Jahren 295-296 unter der Aufsicht des Diokletian erfolgen, da Galerius sich 293-294 in Ägypten aufhielt, dann 295-299 gegen die Persier Krieg führte. Er hielt sich nur im Sommer 297 in Illyricum auf, als er Truppen zum Krieg gegen die Persier sammelte. ${ }^{98}$ Diokletian konnte Galerius mit der Aufsicht der Donauprovinzen vor 299-300 nicht betrauen. Die Ansiedlung der Karpen sollte auch danach in mehreren Schritten erfolgen, da Galerius zwischen 301 und 304 in jedem Jahr das Attribut Carpicum maximus aufnahm. Die endgültige Lösung der Karpen-Frage verzögerte sich also. Das sechste carpicus-Attribut nahm Galerius erst 308-309 oder 310 an. Péter Kovács ist der Meinung, dass die Ansiedlung der Karpen hauptsächlich nach 303 erfolgte. ${ }^{99}$ Das bedeutet, dass die Mehrheit der Karpen mehr als ein Jahrzehnt nach dem Beginn der Wasserregulierungsarbeiten hier angekommen ist. Deshalb ist es kaum wahrscheinlich, dass sie zur Durchführung des Kanalbaus in Valeria angesiedelt wurden.

Den Erfolg der „,großzügigen Investition“ zeigt, dass 30-40 Jahre nach dem Beginn „ohne Vorereignisse“ südlich vom Balaton drei Befestigungen erbaut wurden: in Alsóhetény, Ságvár und Fenékpuszta. In allen drei Befestigungen kamen große horrea zum Vorschein. Aufgrund des Grundrisses versuchten die Verfasser zu bestimmen, wie große Ackerfelder dazu notwendig waren, mit ihrem Ertrag diese horrea füllen zu können. Abhängig davon, ob sie ein oder drei Stöcke besaßen, rechneten sie mit einer Fläche zwischen 3831 und 11494 Hektar. ${ }^{100}$ Diese Schätzung lässt aber außer Acht, dass der Ertrag bei ungünstigem Wetter eventuell nur das Anderthalbfache der Aussaat, bei günstigen Umständen dagegen mehr als das Dreifache sein konnte. Wenn wir also damit rechnen, dass die

${ }^{98}$ Kovács 2011, 33.

${ }^{99}$ KovÁCs 2011, 34 .
${ }^{100}$ PÁszTóKai-SzeŐKe-Serlegi 2013, 71. Laut Zs. Visy konnte das $4500 \mathrm{~m}^{2}$ große horreum von Fenékpuszta das Produkt von etwa 5000 Hektar aufnehmen (VISY 2013, 37). 
horrea in jedem Jahr vollgefüllt wurden, war dazu die Ernte von 4000 bis 23000 Hektar Ackerland nötig. Bei so breiten Grenzwerten hat die Schätzung keinen Sinn. Das bezieht sich auch auf die übrigen geschätzten Angaben.

Aus der Beweisführung der Autoren geht hervor, dass die Innenbefestigungen zum Schutz der horrea erbaut wurden. Befestigte Siedlungen mit horrea sind aber nicht nur aus Valeria, sondern auch aus den Provinzen Raetia II, Germania II und Belgica bekannt. ${ }^{101}$ Sie erwähnen nicht, dass zwei (Ságvár und Alsóheténypuszta) von den drei südlichen Innenbefestigungen zwei Bauperioden haben, wogegen in Fenékpuszta und Környe nur die zweite und in Tác nur die erste Bauperiode nachweisbar ist. Das bedeutet, dass die Befestigungen nicht gleichzeitig gebaut wurden. Über die Bauzeit sind zahlreiche Vorstellungen bekannt. ${ }^{102}$ Unlängst hat Zsolt Visy diese zu den bedeutenden Barbareneinfällen gebunden: Die erste Bauperiode konnte nach den Einfällen 322 oder 332, die zweite nach den Einfällen 356 oder 365 erfolgt sein. ${ }^{103}$

Es war auch bisher bekannt, dass die Innenbefestigungen Pannoniens nicht immer an strategisch geeigneten Stellen, aber ohne Ausnahme neben Wasser aufgebaut wurden. Die Annahme von Endre Tóth, dass sie vor dem Feind quasi „versteckt“ wurden, halte ich für weniger wahrscheinlich. Seiner Meinung nach - aufgrund der Grabungsergebnisse - machte die in diesen Befestigungen vorgenommene Arbeit die Ansiedlung neben Wasser notwendig. Zum Tierschlachten, zur Fleischverarbeitung, zum Schmieden und zum Brotbacken war viel Wasser nötig. ${ }^{104}$ Das hat Zsolt Visy damit ergänzt, dass in den Befestigungen nicht nur Getreide gelagert, sondern auch Großviehzucht getrieben wurde. Zur Tränkung war das reichliche frische Wasser unentbehrlich. ${ }^{105}$

Die Konzeption von J. Pásztókai-Szeőke und Gábor Serlegi ging noch weiter. Wir wissen, wie sehr die Entfernung den Transport in der Römerzeit verteuerte. Deshalb nahmen sie an, dass die Befestigungen neben Wasser angesiedelt wurden, damit die Möglichkeit des Transportes am Wasserweg ausgenutzt werden kann. ${ }^{106}$ Im Fall von Fenékpuszta kann nicht bezweifelt werden, dass die durch das Balaton angebotene Möglichkeit hier benutzt wurde. Dies beschränkte sich aber wahrscheinlich auf den Transport am See, da das Wasser nur dann am Fluss Sió abfloss, wenn der Wasserstand die kritische Höhe erreichte. Wenn die Römer keine Schleuse am Sió-Kanal bauten - und das nahm nicht einmal Gábor Serlegi an,$-{ }^{107}$ dann war der Kanal nicht schiffbar, höchstens nach großen Regenfällen, als der Niederschlag den Wasserstand des Sees plötzlich erhöhte. Das war aber völlig unberechenbar. Von Ságvár hätte man das Balaton nur durch die für die Schifffahrt ungeeigneten Bäche Jaba und Kis-Koppány bzw. durch die bei hohem Wasserstand von Wasser bedeckte Sió-Bucht erreichen können. Ich halte ebenso für unvorstellbar, dass verschiedene Waren von Alsóheténypuszta durch den schmalen Hársasberki-Bach und durch den Fluss Kapos oder von Környe durch das Bach Által-ér mit Schiffen an die Donau transportiert werden konnten. Man hat angenommen, dass die Römer über das Sárvíz schifften, diese Annahme wurde aber bis jetzt durch keine Ausgrabung bestätigt. ${ }^{108}$ Allerdings ist Tác der einzige Ort, wo nur die erste Periode der Befestigungen erbaut wurde. Keiner der Wasserläufe verfügt über genügend Wasser und ein entsprechend tiefes Bett zum Warentransport mit Schiff. Von Spuren der römerzeitlichen Stauwerke haben wir keine Kenntnisse.

Die Autoren haben jedenfalls angenommen, dass der Getreideertrag als Ergebnis der Investition so hoch war, dass der Überschuss der in den horrea der Innenbefestigungen gelagerten Getreide durch den billigen Wasserweg an die Donau und an den Balkan gefördert wurde. Das pannonische Getreide konnte sogar in der Lebensmittelversorgung von Konstantinopel eine Rolle spielen. ${ }^{109} \mathrm{Im}$ pannonischen Münzverkehr des 4. Jahrhunderts ist der Anteil der Prägungen aus dem Balkan bzw. aus dem Osten auffallend hoch, was auf direkte Handelsverbindungen hinweisen könnte. Die Autoren weisen nur auf diese Möglichkeit hin. Wenn Getreide am Balkan verkauft wurde, wurde dafür aber bestimmt nicht mit Kleingeld bezahlt. Sie bemerkten auch, dass „das minderwertige Kleingeld konnte der Rest des nach Hause gebrachten ,Tagegeldes“ der am Transport teilgenommenen Schifffahrer gewesen sein“ “ ${ }^{110}$ Ich bin auch damit nicht einverstanden. Die Möglichkeit eines Getreideexportes beruht in erster Linie auf einer Angabe aus dem Jahr 383. Ambrosius, der Bischof von Mailand berichtete, dass das Mediterraneum von einer

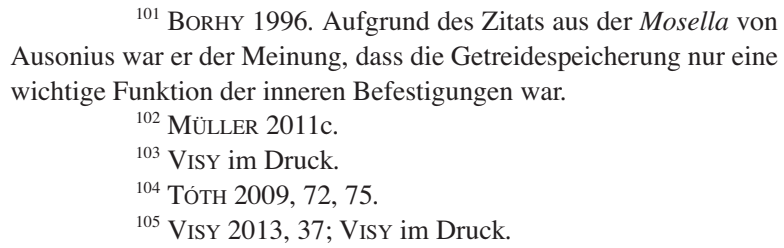

Acta Archaeologica Academiae Scientiarum Hungaricae 67, 2016
${ }^{106}$ PÁsZTóKAI-SZEŐKE 2012a, 20-21; PÁSZTÓKAI-SZEŐKE 2013a, 213; PÁSZTÓKAI-SZEŐKE-SERLEGI 2013, 71.

${ }^{107}$ SERLEGI 2007, Abb. 14.

${ }^{108}$ FITZ 2003, 29 bei Tác bzw. NÁDORFI 2013, 133 und Abb. 14 bei der Siedlung von Szabadbattyán haben einen Hafen vorausgesetzt.

${ }^{109}$ Pásztókai-SZEŐKe-SERLegi 2014, 58.

${ }^{110}$ PÁsZTóKAI-SZEÕKe-SERLEgi 2013, 73. 
großen Dürre betroffen wurde, deshalb war der Getreideertrag niedrig. In Pannonien war die Ernte aber gut und der Überschuss wurde verkauft. ${ }^{111}$ Ambrosius schilderte wahrscheinlich nicht die Verhältnisse am Balkan und nach Norditalien konnte das Getreide aus Pannonien am Wasserweg sowieso nicht transportiert werden. Wir haben keinen Grund anzunehmen, dass dies durch eine längere Zeit, jährlich geschah. Beim Transport am Festland verdoppelt sich der Preis eines Getreidewagens pro $480 \mathrm{~km} .{ }^{12}$ Zwischen Pécs (Fünfkirchen) und Mailand ist die Entfernung in Luftlinie 704 km, laut Fahrstraßenplanung ist es 896-904 km. Im 4. Jahrhundert musste man mindestens $1000 \mathrm{~km}$ zwischen den beiden Ortschaften zurücklegen. Das bedeutet, dass der Preis des Getreides aus Valeria auf das Dreifache stieg, bis es in Mailand ankam.

Wir haben auch eine weitere unsichere Quelle, das Expositio totius mundi et gentium, was ein Autor mesopotamischer oder syrischer Abstammung in der Mitte des 4. Jahrhunderts zusammenstellte. Die Schrift stellt Pannonien als eine reiche Provinz vor, die unter anderen auch Getreide exportiert. ${ }^{113}$ Auch A. Mócsy nahm an, dass das pannonische Getreide am Wasserweg transportiert wurde. Er war aber der Meinung, dass dieses Getreide an den Großgrundbesitzen entlang der Donau, der Drau und der Save produziert wurde. ${ }^{114}$ Es ist gar nicht sicher, dass in den horrea der Innenbefestigungen nur pannonisches Getreide gelagert wurde. „Miklós Füzes untersuchte die Artzusammensetzung der in kleiner Zahl gefundenen Unkrautsamen und schloss auf Importgetreide. Seiner Meinung nach haben solche Unkrautarten wie Kornrade, Hohldotter (Myagrum perfoliatum) und Neslea paniculata ursprünglich eine mediterrane Verbreitung, so ist es sehr wahrscheinlich, dass das in Fenékpuszta gefundene Getreide auch aus diesem Gebiet stammt. “"115 Wir müssen also mit der Möglichkeit rechnen, dass von Zeit zu Zeit auch Importgetreide in den horrea der Innenbefestigungen gelagert wurde.

Zusammenfassend kann also festgestellt werden, dass die Vorstellung von J. Pásztókai-Szeőke und Gábor Serlegi über eine 292 gestartete, zentral geplante, mehrere Jahrzehnte lang andauernde, in Südtransdanubien verwirklichte grandiose Agrar-Großinvestition die Probe der Kritik nicht besteht.

Der Webkamm (pecten) und der irrtümlich mit dem Fadenordner (radius) identifizierte, 20-30 cm lange, an einem Ende zugespitzte Handspinnrocken (colus) wurden in Pannonien in der Spätkaiserzeit auch aus Eisen hergestellt. Die Zahl der Letzteren ist deshalb so hoch, weil er hauptsächlich in Südtransdanubien gerne als Beigabe in die Frauengräber gelegt wurde. Da diese Spinn- und Webgeräte früher aus organischem Material hergestellt wurden, wissen wir nicht, ob ihre Zahl im Vergleich zu den früheren Jahrhunderten tatsächlich wesentlich zunahm. Die Webkämme waren zum Erzeugen von Knüpfteppichen oder von Textilien mit farbigen Mustern nicht geeignet. Daraus folgt aber bei Weitem nicht, dass sie ausschließlich zur Herstellung von Leinwand benutzt wurden.

Das günstige Klima der Frühkaiserzeit wurde von der Wende des 2.-3. Jahrhunderts an kühler und regnerischer, deshalb erhöhte sich stufenweise der Wasserstand des Balaton. Zum Schutz der Siedlungen und Ackerfelder am Seeufer leitete Kaiser Galerius im Jahre 292 Wasserregulierungsarbeiten ein. Wir wissen nicht, wie erfolgreich diese Tätigkeit war, da die Auswertung der archäologischen Fundorte, die eine bedeutende Wasserniveausenkung beweisen konnten, falsch war. Die Uferlinie des Balaton war im 4. Jahrhundert, als die Befestigung erbaut wurde, weiter drinnen. Der NO-Teil der Befestigung wurde im 16.-17. Jahrhundert vom See weggeschwemmt. Die Einwohner haben die Siedlung am Fundort Balatonlelle-Kenderföld in der Mitte des 3. Jahrhunderts verlassen. Als sie nach einem Jahrhundert zurückkehrten, haben sie ihre Häuser an einem höheren Niveau neu aufgebaut. Daraus folgt, dass Galerius sich mit der Verhinderung des weiteren Anstiegs des Wasserstandes zufriedengab. Das bedeutet aber, dass man am Südufer des Balaton keine ausgedehnten neuen Ackerfelder gewonnen konnte. Wir wissen auch nicht, wie erfolgreich die Rodung der Wälder war.

Von der Regierungszeit des Kaisers Aurelian an wurden in mehreren Stufen Karpen in das Reich eingesiedelt, so auch in den Jahren 295-296. Schriftliche Quelle bestätigt, dass Karpen in Südtransdanubien, in der Provinz Valeria, angesiedelt wurden. Galerius hat wahrscheinlich hauptsächlich nach 303, also mehr als ein Jahrzehnt nach dem Start der Wasserregulierungsarbeit, die Karpen angesiedelt, deshalb kann dieses Ereignis mit dem Kanalbau nicht direkt in Zusammenhang gebracht werden.

${ }^{111}$ Ambrosius: Epistolae 18.23.

${ }^{112}$ PÁszTóKAI-SZEỎKE-SERLEGI 2013, 71.

${ }^{113}$ Expositio totius mundi 57. Ich halte die Quelle für unsicher, weil die Provinzen an der Unteren Donau, die bedeutende Getreideproduktion hatten, laut Verfasser nur den eigenen Bedarf decken konnten. Pannonien wurde mit Noricum gemeinsam behandelt und von dort hielt er nur den Kleiderexport für bedeutend.

${ }^{114}$ Mócsy 1974, 155-156.

${ }^{115}$ GyUlai 2005, 269. 
Im 4. Jahrhundert wurden innere Befestigungen in zwei Stufen gebaut. In Alsóhetény und Ságvár haben die Befestigungen zwei Perioden. Aus Tác ist nur die erste, aus Fenékpuszta und Környe nur die zweite Periode bekannt. Die Befestigungen waren eine Art „logistische Zentren“ mit einem heutigen Ausdruck, sie waren Nachschub- und Versorgungsbasen des limes. Daneben waren sie zur Aufnahme des beweglichen Heeres, des comitatenses, geeignet. In Alsóhetény, Ságvár und Fenékpuszta standen riesige horrea in den Befestigungen, die Befestigungen wurden aber nicht wegen der horrea gebaut. Diese waren Teile des dreifach gegliederten Verteidigungssystems und sie wurden nach den zerstörerischen Einfällen der Barbaren erbaut.

Alle Befestigungen befinden sich in Wassernähe. Das kann mit der hier vorgenommenen Arbeit und mit dem Wasserbedarf der hiesigen Großviehzucht erklärt werden - und nicht damit, dass der Wassertransport billig war. Neben den Befestigungen von Alsóheténypuszta, Ságvár, Fenékpuszta, Tác und Környe befanden sich nur für den Warentransport mit Schiff ungeeignete, unbedeutende Bäche. Man konnte die Donau sogar aus Fenékpuszta mit Schiffen fortdauernd nicht erreichen - nicht einmal nach den Wasserregulierungsarbeiten.

Aus dem Brief von Ambrosius, Bischof von Mailand, geht hervor, dass im Jahr 383 Getreide aus Pannonien nach von der Dürre heimgesuchtem Italien geliefert wurde. Nur unsichere Angaben sprechen darüber, dass aus Pannonien regelmäßig Getreide in andere Gebiete des Reiches transportiert wurde. Aufgrund archäobotanischer Angaben kann sogar angenommen werden, dass von Zeit zu Zeit auch Importgetreide in den horrea der Innenbefestigungen gelagert wurde.

All das bedeutet aber nicht, dass sich in den Jahrhunderten der Römerzeit keine wesentlichen Änderungen abgespielt hätten. Die Provinz glandifera Pannonia wurde zu einer Provinz mit hoher Kultur, die auch aus Getreide selbstversorgend wurde, zeitweise sogar exportierte. Aufgrund der großen kaiserlichen Latifundien, der im 4. Jahrhundert umgebauten oder neu gegründeten Villenwirtschaften und der großen Gräberfelder zeigen die stark gewordenen ländlichen Siedlungen, dass Pannonien trotz der verheerenden Barbareneinfälle bis Ende des 4. Jahrhunderts eine blühende, reiche Provinz blieb.

\section{LITERATUR}

BALÁzs 2015

BENDEFY-V. NAGY 1969

T. Bíró 1994

BLÜMNER 1912

BORHY 1996

BORHY 2014

BORHY 2015

SZ. BURGER 1968

Sz. BURGER 1972

SZ. BURGER 1977

Sz. BURGER 1979

DEMÉNY et al. 2010

DOMBAY 1957

FACSÁDY 2008
= P. BALÁzs: A szentély kútjának leletei [Die Funde des Brunnens im Sanktuarium]. In: O. SostaricsP. Balázs-A. Csapláros (szerk.): A savariai Isis-szentély I. Isis savariai otthona - Kiállítási katalógus. Sistrum - Serie A 1. Szombathely 2013 [2015], 279-288.

= L. BENDEFY-I. V. NAGY:A Balaton évszázados partvonalváltozásai [Veränderungen des Balatonufers während der Jahrhunderte]. Budapest 1969.

= M. T. Bíró: The Bone Objects of the Roman Collection. Catalogi Musei Nationalis Hungarici. Ser. Arch. 2. Budapest 1994.

= H. BLÜMNER: Technologie und Terminologie der Gewerbe und Künste bei Griechen und Römern. Leipzig-Berlin 1912.

= L. BORHY: „Non castra sed horrea... “ Bestimmung einer der Funktionen spätrömischer Binnenfestungen. BVbl 61 (1996) 207-224.

= L. BORHY: Die Römer in Ungarn. Darmstadt 2014.

= L. BORHY: A rómaiak Magyarországon [Die Römer in Ungarn]. In: M. Szabó-L. Borhy: Magyarország története az ókorban: kelták és rómaiak. Budapest 2015, 83-229.

= A. Sz. BuRGER: Késő római sírok Halimbán (Spätrömische Gräber in Halimba). FolArch 19 (1968) 87-98.

= A. Sz. BuRGER: Római kori temető Majson (Ein römerzeitliches Gräberfeld in Majs). ArchÉrt 99 (1972) 64-100.

= A. Sz. Burger: Késő római sírok Mucsfa-Szárász-pusztán (Spätrömische Gräber in MucsfaSzárász-puszta). ArchÉrt 104 (1977) 189-203.

= A. Sz. BURGER: Das spätrömische Gräberfeld von Somogyszil. FontArchHung. Budapest 1979.

= A. Demény-G. Schöll-Barna-Z. Siklósy-M. Bondár-P. SÜmegi-G. Serlegi-Sz. FábiánI. FóRIzs: Az elmúlt ötezer év éghajlatváltozási eseményei a Kárpát-medencében és társadalmi hatásaik [Klimaveränderungen im Karpatenbecken in den vergangenen fünftausend Jahren und ihre gesellschaftlichen Wirkungen]. Klíma-21 Füzetek 59 (2010) 82-94.

$=\mathrm{J}$. DomBAY: Késő római temetők Baranyában (Spätrömische Friedhöfe im Komitat Baranya). JPMÉ 1 (1957) 181-330.

= A. R. FACSÁdY: Glass Distaff From Aquincum: Symbol or Tool? Andos. Studies of the Ancient World 8 (2008) 165-173. 
FITZ 2003

GAITSCH 1980

GosTENČNIK 2011

GotTSCHALK 1993

GRYNEUS 2004

GyUlai 2005

HABEREY 1949

HENNING 1987

HOOK-MACGREGOR 1997 KovÁcs 2011

KREMPUŠ 2000

KUZSINSZKY 1920

LANDGRAF-SZITTNER 1984 LIPP 1886

MARICHAL 2000

Marton-SERLEGI 2004

MóCSY 1974

MÜLLER 1979

MÜLLER 1982

MÜLLER 1994

MÜLLER 2009

MÜLLER 2011a

MÜLLER 2011b

MÜLLER 2011c

MÜLLER 2012

MÜLLER 2014a

MÜLLER 2014b

NÁDORFI 2013
= J. FITZ: Gorsium - Herculia. Székesfehérvár 2003.

= W. GAITSCH: Eiserne römische Werkzeuge. BAR IntSer 78. Oxford 1980.

= K. GostenČNIK: Aus dem Augen - aus dem Sinn? Hölzerne Textilgeräte und ihre Nachweisbarkeit. In: P. Scherren (Hrsg.): Lignum. Holz in der Antike. Akten des öffentlichen interdisziplinären Symposiums im Rahmen des Überfakultären Doktoratsprogramms „Antike Kulturen des Mittelmeerraums“. Graz 2011, 207-240.

= R. GotTSCHALK: Ein spätrömischer Spinnrocken aus Elfenbein. AKorr 26 (1996) 483-500.

= A. GRYNEUS: A magyarországi dendrokronológiai kutatás eredményei és új kérdései [Ergebnisse und neue Fragen der dendrochronologischen Forschung in Ungarn]. In: „Es tu scolaris.” Ünnepi tanulmányok Kubinyi András 75. születésnapjára. MHB 13. Budapest 2004, 87-102.

= F. GyulAI: Archaeobotanikai kutatások a Balaton környékén (Archaeological researches around Lake Balaton). ZalaiMúz 14 (2005) 263-297.

= W. HABEREY: Ein spätrömisches Frauengrab aus Dornweiler, Kr. Euskirchen. BJ 149 (1949) 82-93.

$=$ J. HenNING: Südosteuropa zwischen Antike und Mittelalter. Schriften zur Ur- und Frühgeschichte 42. Berlin 1987.

= M. HoOK-A. MACGREGoR: Medieval England - From Alfred The Great to Richard III. Oxford 1997.

= P. KovÁcs: A karpok betelepítése Pannoniába [Ansiedlung der Karpen in Pannonien]. Studia Epigraphica Pannonica 3 (2011) 31-38.

= R. KREMPUŠ: Krvavica bei Vransko in Slowenien, Höhensiedlung des 3. bis 6. Jahrhunderts. In: M. Feugère-M. Guštin (eds): Iron, Blacksmiths and Tools. Ancient European Crafts. Monographies instrumentum 12. Montagnac 2000. 209-231.

= B. KuZsinsZKY: A Balaton környékének archaeológiája [Archäologie der Umgebung des Balaton]. Budapest 1920.

= K. LANDGRAF-A. SzitTNeR: Szövés [Das Weben]. Budapest 1984.

= V. LIPP: A fenéki sírmező [Das Gräberfeld von Fenék]. ArchKözl 14 (1886) 137-159.

$=$ R. MARICHAL: Outillage antique de Ruscino (Château-Roussillon, Pyrènèes-Orientales, F). In: M. Feugère-M. Guštin (eds): Iron, Blacksmiths and Tools. Ancient European Crafts. Monographies instrumentum 12. Montagnac, 2000, 139-168.

= T. MARTON-G. SerLegi: Balatonlelle-Kenderföld (M7/S20 lh.). In: A tervezett M7-es autópálya Somogy megyei szakaszának megelőző régészeti feltárása (2002-2003). Előzetes jelentés III. SMK 16 (2004) $15-18$

= A. Mócsy: Pannonia a késői császárkorban [Pannonien in der Spätkaiserzeit]. Apollo könyvtár 4. Budapest 1974.

= R. MÜLLER: A Keszthely-fenékpusztai erőd északi kapujának feltárása 1971-ben - Ásatási jelentés (Die archäologische Erschließung des Nord-Tores der Befestigung von Keszthely-Fenékpuszta im Jahre 1971 - Ausgrabungsbericht). VMMK 14 (1979) 123-156.

= R. MÜLLER: A mezőgazdasági vaseszközök fejlődése Magyarországon a késővaskortól a törökkor végéig (Die Entwicklung der eisernen Agrargeräte in Ungarn von der Späteisenzeit bis zum Ende der Türkenherrschaft). ZalaiGyüjt 19/I-II. Zalaegerszeg 1982.

= R. MÜLLER: A balatonaligai vaseszközök (Eisengeräte aus Balatonaliga). VMMK 19-20 (19931994) [1994] 177-193.

= R. MÜLLER: Guzsalyok és orsógombok Pannóniában [Spinnrocken und Spinnwirtel in Pannonien]. ZalaiMúz 18 (2009) 39-54.

= R. MÜLLER: Spinnrocken aus Metall und Spinnwirtel im spätkaiserzeitlichen Pannonien. ActaArchHung 62 (2011) 175-195.

= R. MÜLLER: Szokatlan épitési megoldások a keszthely-fenékpusztai késő római erődnél (Unfamiliar construction solutions at the fortress Keszthely-Fenékpuszta). Arrabona 49/1 (2011) 239-250.

= R. MÜLLER: Mikor épült a keszthely-fenékpusztai késő római erőd? (Wann wurde die spätrömische Festung von Keszthely-Fenékpuszta erbaut?) MFMÉ-StudArch 12 (2011) 145-153.

= R. MÜLLER: Késő római vaseszköz lelet Vindornyafokról (Ein spätrömischer Eisengerätfund aus Vindornyafok). ZalaiMúz 20 (2012) 167-188.

= R. MÜLLER: A középkor agrotechnikája a vaseszközök alapján (Agricultural techniques in the Middle Ages in light of iron tools). Ethnographia 125 (2014) 1-19.

= R. MÜLLER: Temetőrészlet Zalaegerszeg-Kaszaházáról. Újabb késő római sír vasguzsallyal és orsóval (The cemetery section at Zalaegerszeg-Kaszaháza. A new Late Roman grave with distaff and spindle). In: A. Anders-Cs. Balogh-A. Türk (szerk.): Avarok pusztái. Régészeti tanulmányok Lőrinczy Gábor 60. születésnapjára. Budapest 2014, 65-72.

= G. NÁDORFI: Előzetes jelentés a szabadbattyáni késő római kori épület feltárásáról (Preliminary report on the excavation of the Late Roman building at Szabadbattyán). In: Zs. Visy (ed.): A SEUSOkincs és Pannonia - The SEVSO Treasure and Pannonia. Pécs 2013, 112-138. 
NOVÁKI 2006

OWEN-CROCKER 2004

ÖZER 2009

PÁSZTÓKAI-SZEŐKE 2007

PÁSZTÓKAI-SZEŌKE 2010

PÁSZTÓKAI-SZEŌKE 2011

PÁSZTÓKAI-SZEŐKE 2012a

PÁSZTÓKAI-SZEŐKE 2012b

PÁSZTÓKAI-SZEŐKE 2013a

PÁSZTÓKAI-SZEŐKE 2013b

PÁSZTÓKAI-SZEŐKE-SERLEGI 2013

PÁsZTÓKAI-SzEŐKE-SERLEGI 2014

V. PÉterfi 1993

PetTy 2014

PIRLING 1976

RÓMER 1862

SÁGI 1960

SÁGI 1973

SÁGI 1981

SÁGI 1989

SERLEGI 2007

SERLEGI-MARTON 2004

SteinKLAUBER 2013
= GY. NovÁKI: Kataster der prähistorischen Erdburgen Ungarns - Versuch einer umfassenden Datenerfassung zum Schutz des kulturellen, archäologischen und naturräumlichen Erbes. In: A. KrennLeeb (Hrsg.): Wirtschaft, Macht und Strategie. Höhensiedlungen und ihre Funktionen in der Ur- und Frühgeschichte. Wien 2006, 125-139.

= G. R. Owen-Crocker: Dress in Anglo-Saxon England. Manchester 2004.

= E. ÖZER: Berufsdarstellungen auf römischen Sarkophagen. Diplomarbeit, Universität Wien. Wien 2009. google.hu\#q=özer+berufsdarstellungen

= J. PÁSZTÓKAI-SZEŌKE: Római textilművesség régészeti hagyatéka Pannoniában (Die archäologische Nachlassenschaft des römischen Textilgewerbes in Pannonien). FiRKáK I. Györ 2007, 185-190.

= J. PÁSZTÓKAI-SzEŐKE: Lóvakaró vagy szövőszerszám? Római kori fogazott vasszerszámok Pannonia területéröl [Striegel oder Webgerät? Römerzeitliche gezähnte Eisengeräte aus Pannonien]. Alba Regia 39 (2010) 251-255.

= J. PÁsZTÓKAI-SzEŐKE: Curry-comb or toothed werft beater? The serrated iron tools from the Roman Pannonia. Archaeological Textiles Newsletter 52 (2011) 3-13.

= J. PÁszTóKAI-SzEőKE: Vasból készült szövőeszközök és textilmüvesség a 4. századi Dunántúlon (Iron weawing tools and textile production in Transdanubia during the fourth century AD). In: Zs. Petkes (ed.): Hadak útján XX. Népvándorláskor Fiatal Kutatói XX. Összejövetelének konferenciakötete. Budapest 2012, 15-26.

= J. PÁszTóKAI-SzEŐKE: „Amíg az anya fogy, a gyermek hízik. Mi az?” Gondolatok ókori nőkkel kapcsolatos társadalmi elvárásokról a scarbantiai borostyánguzsalyok kapcsán [,Während die Mutter abnimmt, nimmt das Kind zu. Was ist das?" Gedanken über die gesellschaftlichen Erwartungen die Frauen der Antike betreffend in Zusammenhang mit den Spinnrocken aus Bernstein von Scarbantia]. SSz 66 (2012) 5-19.

= J. PÁsZTÓKAI-SzEŐKE: Technologischer Wandel in der Textilproduktion Pannoniens unter römischem Einfluss. In: M. Tellenbach-R. Schulz-A. Wieczorek (Hrsg.): Die Macht der Toga. Dresscode im römischen Weltreich. Mannheim 2013, 209-214.

= J. PÁSZTÓKAI-SZEŐKE: Following a clew: From tools to textile production in Roman Pannonia. In: J. Bank-Burgess-C. Nübold (eds): NESA XI. The North European Symposium for Archaeological Textlies XI. 10-13 May 2011 in Esslingen am Neckar. Rahden 2013, 257-262.

= J. PÁsztóKaI-SzeỏKe-G. Serlegi: De mit tettek értünk a rómaiak? Textilművesség, klíma és a Balaton a Kr. u. 4. századi Dunántúlon [Aber was haben die Römer für uns getan? Textilproduktion, Klima und der Balaton in Transdanubien im 4. Jahrhundert n. Chr.]. Ókor 2013/3, 68-79.

= J. PÁSZTÓKAI-SZEŐKE-G. SERLEGI: De mit tettek értünk a rómaiak? Radikális környezetátalakítás a Dél-Dunántúlon [Aber was haben die Römer für uns getan? Radikale Umweltveränderung in Südtransdanubien]. BBC History 2014/11, 57-61.

= Zs. V. PÉTERFI: A Bátaszék-Kövesd pusztai késő római temető (Der spätrömische Friedhof von Bátaszék-Kövesd puszta). WMMÉ 18 (1993) 47-168.

= Chr. PetTy: Warp Weighted Loom: Than and Now. Anglo-Saxon and Viking Archaeological Evidence and Modern Practitioners. Manuscript, University of Manchester. Manchester 2014. www. escholar.manchester.ac.uk

= R. PIRLING: Klothos Kunkel. In: T. E. Haevernick-A. von Salden (Hrsg.): Festschrift für Waldemar Haberey. Mainz 1976, 101-109.

= F. RÓMER: Pannónia területén Magyarországon fennmaradt néhány római várnáról [Über die in Ungarn, im Gebiet Pannoniens verbliebenen etlichen römerzeitlichen Castra]. ArchKözl 3 (1862) 36-53.

= K. SÁGI: Die spätrömische Bevölkerung der Umgeung von Keszthely. ActaArchHung 12 (1960) $187-256$.

= K. SÁGI: Római téglasír Balatonberényben és ókeresztény kapcsolatai (Ein Ziegelgrab in Balatonberény und seine altchristlichen Zusammenhänge). SMK 1 (1973) 289-297.

= K. SÁGI: Das römische Gräberfeld von Keszthely-Dobogó. FontArchHung. Budapest 1981.

= K. SÁGI: Adatok a fenékpusztai erőd történetéhez (Über die Geschichte der Festung in Fenékpuszta). TapolcaVMK 1 (1989) 261-317.

= G. SERLEGI: A balatonkeresztúri ,vízmérce”. Környezetrégészeti információk a Balaton déli partjának római kori történetéhez (Die „Wasserwaage“ von Balatonkeresztúr. Archäoökologische Informationen zur Geschichte am Südufer des Plattensees in der Römerzeit). FiRKáK I. Győr 2007, 297-317.

= G. Serlegi-T. Marton: Balatonlelle-Kenderföld. In: RégKut 2002. Budapest 2004, 175-176.

$=$ U. STEINKLAUBER: Fundmaterial spätantiker Höhensiedlungen in Steiermark und Kärnten. Frauenberg im Vergleich mit Hoischhügel und Duel. Forschungen zur geschichtlichen Landeskunde der Steiermark 61. Graz 2013. 
SÜMEGI et al. 2007

SZOLNOKY 1951

SZOLNOKY 1991

TóTH 2009

B. VÁGÓ-BÓNA 1976

VAJDA 2014

VIRÁG 1998

VIRÁG 2005

VISY 2013

VISY im Druck

WALTON Rogers 2007

ZIMMER 1982

ZIMMER 1985
= P. SüMegi-E. Bodor-I. JuhÁsZ-Z. Hunyadfalvi-K. Hebrich-S. MolnáR-G. TímÁR: A Balaton déli partján feltárt régészeti lelőhelyek környezettörténeti feldolgozása [Die umweltgeschichtliche Verarbeitung der archäologischen Fundstellen am Südufer des Balaton]. In: K. BelényesiSz. Honti-V. Kiss (szerk.): Gördülő idő. Régészeti feltárások az M7-es autópálya Somogy megyei szakaszán Zamárdi és Ordacsehi között. Kaposvár 2007, 241-253.

= L. Szolnoky: Az Országos Néprajzi Múzeum guzsalygyüjteménye [Die Spinnrockensammlung des Ungarischen Landesmuseums für Völkerkunde]. Budapest 1951.

= L. Szolnoky: A kender, a len és a gyapjú népi feldolgozása [Die traditionelle Verarbeitung des Hanfs, des Flachses und der Wolle]. In: O. Domonkos (Hrsg.): Magyar néprajz. 3: Kézmüvesség. Budapest 1991, 341-368.

= E. Tóтн: Studia Valeriana. Az alsóhetényi és ságvári késő római erődök kutatásának eredményei [Die Ergebnisse der Erforschung der spätrömischen Befestigungen von Alsóhetény und Sárvár]. Dombóvár 2009.

= E. B. VÁGÓ-I. BóNA: Die Gräberfelder von Intercisa. I: Der spätrömische Südwestfriedhof. Budapest 1976.

= T. VAJDA: Adatok és észrevételek a Balaton 3-15. század közötti vízállásához [Angaben und Bemerkungen zum Wasserstand des Balaton zwischen dem 3. und 15. Jahrhundert]. Belvedere Meridionale 26/3 (2014. Ösz) 49-62.

= Á. VIRÁG: A Balaton múltja és jelene [Vergangenheit und Gegenwart des Balaton]. Eger 1998.

= Á. VIRÁG: A Sió és a Balaton közös története (1055-2005)-Ein geschichtlicher Überblick über die wechselseitige Beziehung zwischen dem Balaton und dem Fluss Sió (1055-2005). Budapest 2005.

= Zs. VISY: A késő római vidéki települések szerepe és jelentősége Valeriában (The role and significance of the late Roman rural settlements in Valeria). In: Zs. Visy (ed.): A SEUSO-kincs és Pannonia - The SEVSO treasure and Pannonia. Pécs 2013, 35-48.

= Zs. VISY: Some considerations on the late Roman inner defence of Pannonia. Vortrag am XXIII. Limes-Kongress in Ingolstadt 2015. Im Druck.

$=$ P. Walton Rogers: Cloth and Clothing in Early Anglo-Saxon England AD 450-700. CBA Research Report 145. York 2007.

= G. ZIMMER: Römische Berufsdarstellungen. Archäologische Forschungen 12. Berlin 1982.

= G. ZIMMER: Römische Handwerker. In: ANRW II/12.3. Berlin-New York 1985. 